$$
\text { بسم الله الرحمن الرهيم }
$$

$$
\text { الرقابة الإدارية ودورها في تحقيق الأهداف }
$$

$$
\begin{aligned}
& \text { د/ محمد نشوان الواكي } \\
& \text { أستاذ إدارة الأعمال المساعد } \\
& \text { كلية المجتمع ببربدة } \\
& \text { جامعة القصيم }
\end{aligned}
$$




\section{ملذص الدراسة}

تهدف الدراسة الى معرفة دور الرقابة الادارية في تحقيق الاهداف لقطاع الاعمال في القصيم والذي

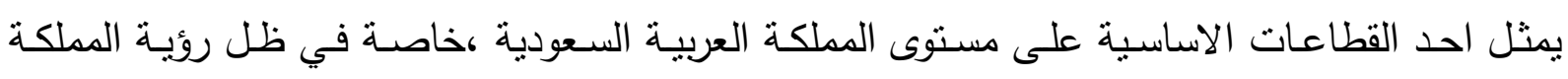

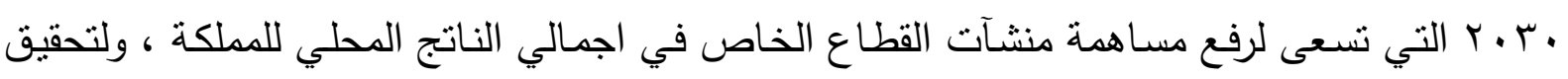

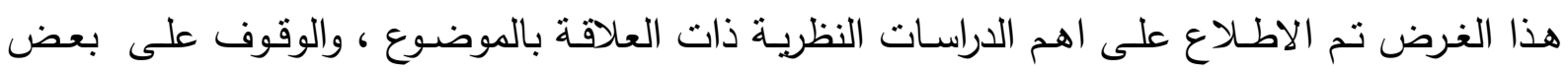

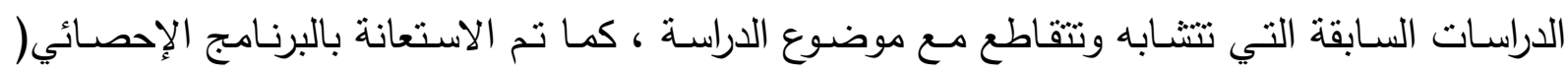

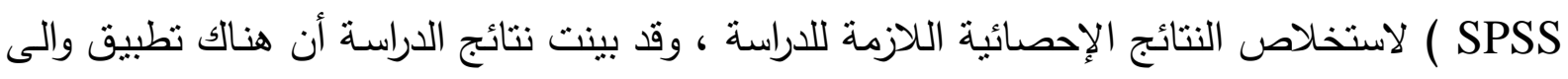

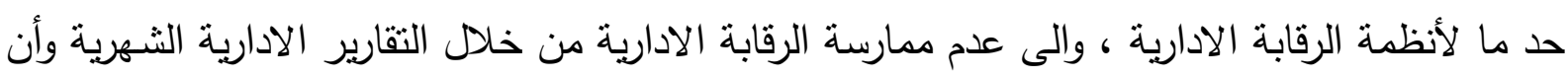

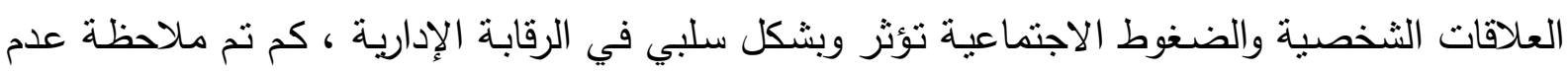

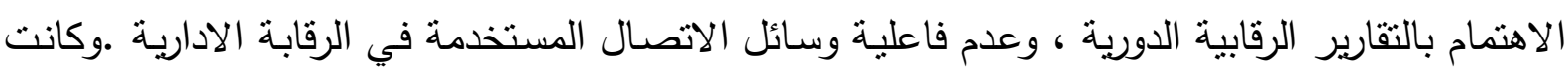

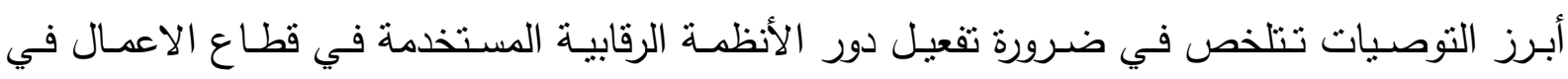

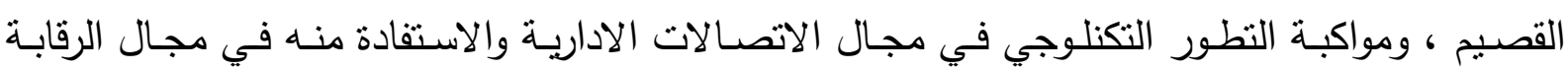

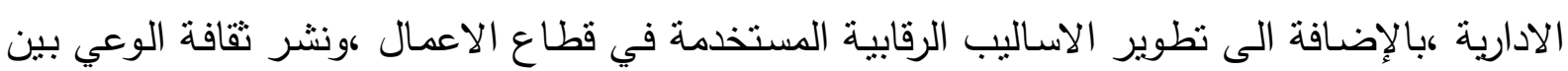

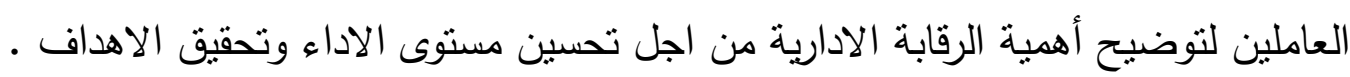




\section{Study Summary}

The objective of the study is to know the role of administrative control in achieving the objectives of the business sector in Qassim, which is one of the main sectors in the Kingdom of Saudi Arabia, especially in view of the Kingdom's vision 2030, which seeks to increase the contribution of private sector enterprises in the Kingdom's gross domestic product, In order to achieve this purpose, the most important theoretical studies related to the subject were examined, and some previous studies that are similar and intersect with the subject of the study, The statistical program (SPSS) was also used to derive the statistical results needed for the study, The results of the study have been based on the fact that there is some application and to some extent of the administrative control systems, the lack of administrative control through the monthly administrative reports, and the personal relations and social pressures negatively affect the administrative control, Note the lack of interest in periodic control report، And the lack of effective means of communication used in administrative control, And the lack of effective means of communication used in administrative control, and the most prominent recommendations are the need to activate the role of regulatory systems used in the business sector in Qassim, And to keep abreast of the technological development in the field of administrative communication and benefit from it in the field of administrative control, in addition to developing the supervisory methods used in the business sector, and spreading the culture of awareness among the employees to clarify the importance of supervision in order to improve the level of performance and achieve goals. 
تعد الرقابة الادارية من العناصر الأساسية للعملية الادارية والتي تثمل التخطيط والتتظيم والقيادة

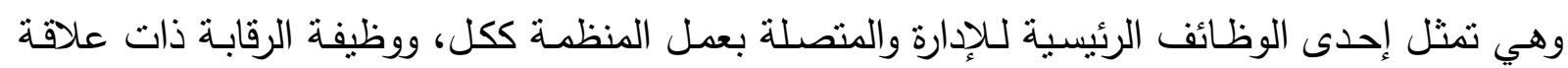
وثثة بباقي الوظائف الادارية الاخرى وبوظيفة التخطيط على وجه الخصوص ، ويمكن النظر اليهما -

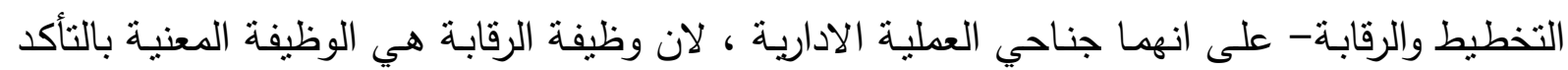

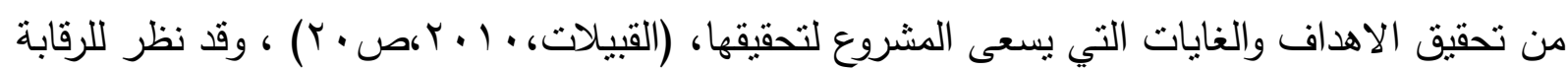

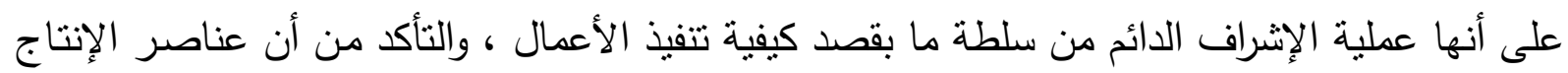

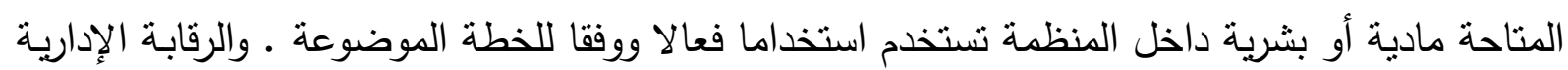
وفقا لهذا المفهوم هي تعبير شامل عن الإثراف والمتابعة وقياس الأداء وتحديد المعايير ومقارنتها بالنتائج

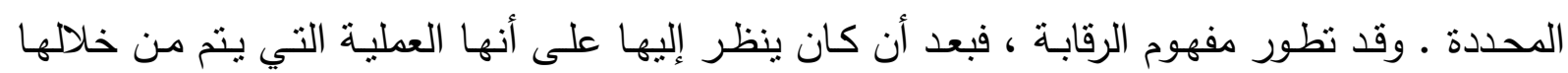

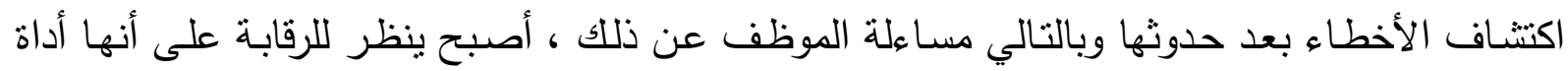

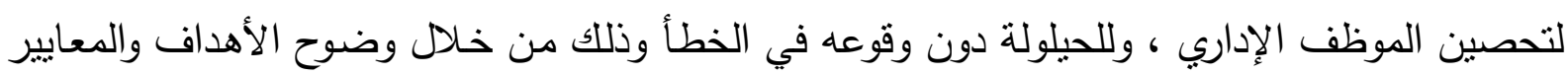

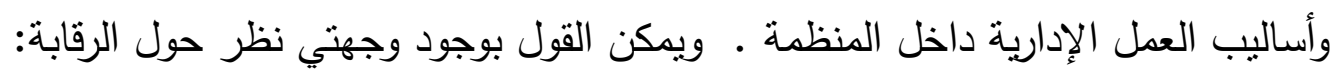
الاولى : وهي التي تعكس وجهة النظر التقليدية والتي تركز على الرقابة كأداة تخويف واكراه والبـ واجبار

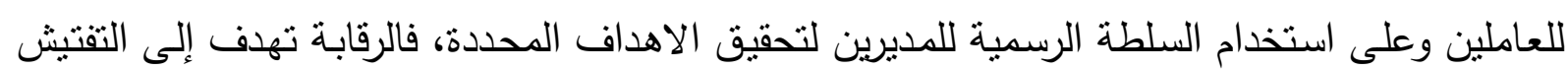

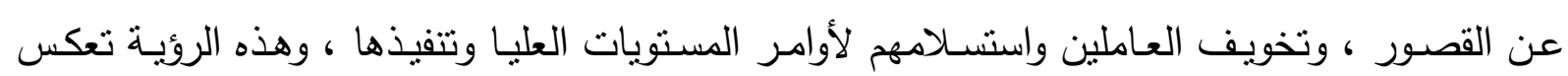

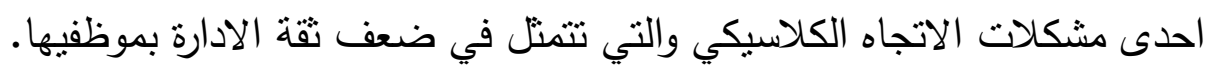

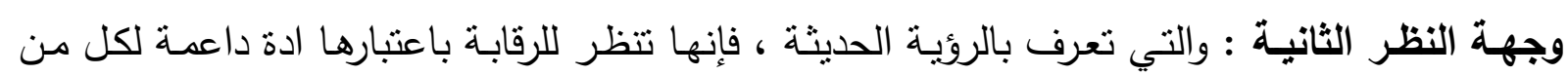

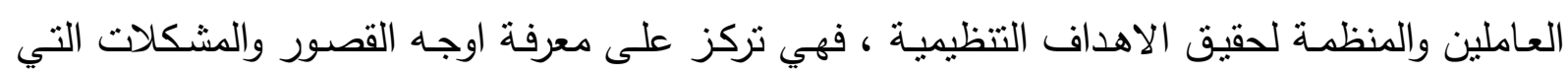

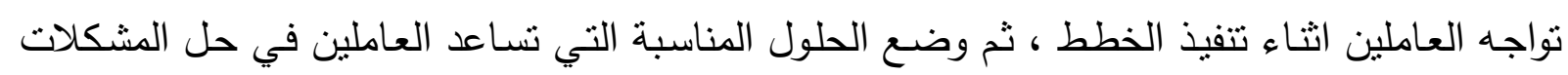
والتظلب على جوانب القصور ، ومن ثم دعم العاملين على تحقيق مستويات اعلى من الفعالية التتظيمية

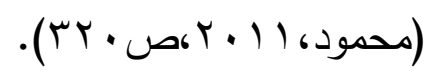

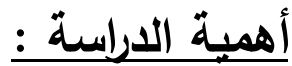

تتبثق أهمية الدراسة من أهية موضوع الرقابة الإدارية ذاتها في منظمات الأعمال وما يعول عليها

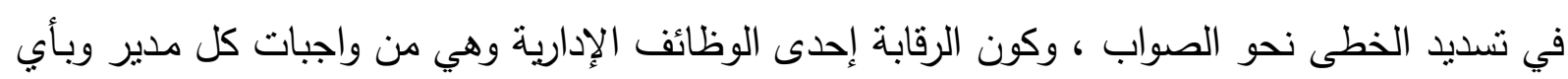

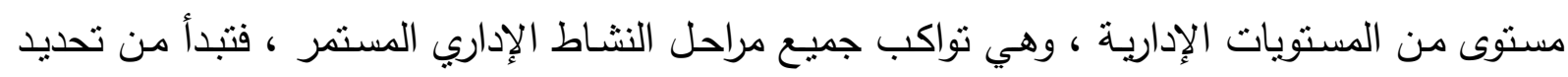

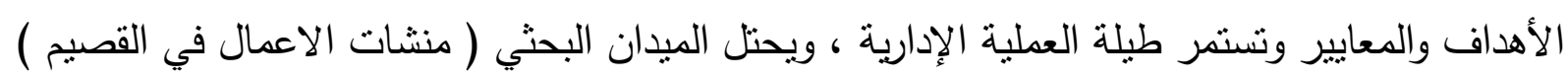

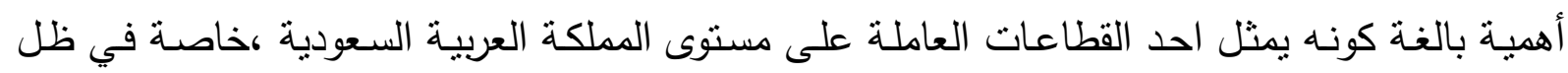


رؤية المملكة •r.r.r والتي تسعى لرفع مساهمة منشات القطاع الخاص في اجمالي الناتج المحلي من

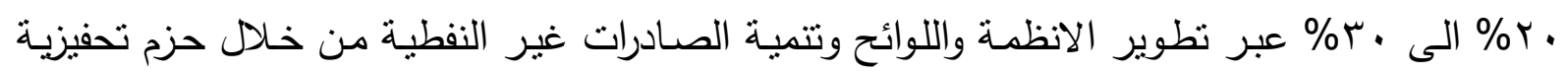

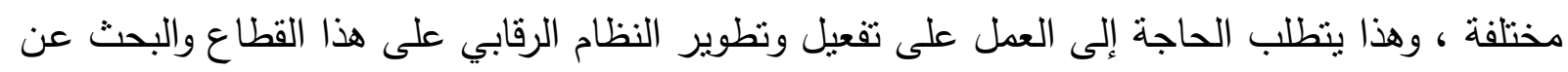

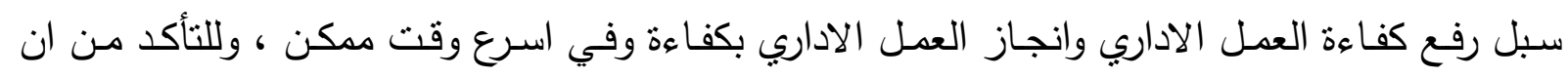

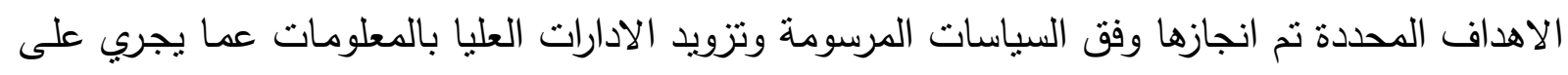

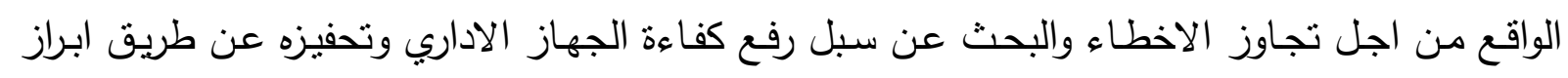

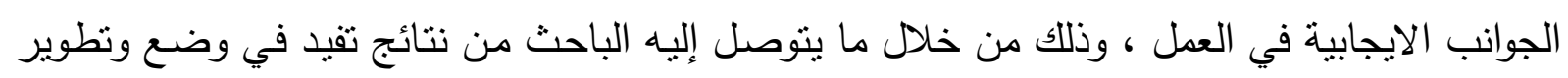

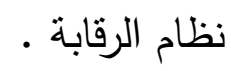

\section{أهداف الادراسة :}

يتمثل هدف الدراسة في العمل على وضـع إطار فاعل ومتكامل لمرتكزات الرقابة على الأنشطة

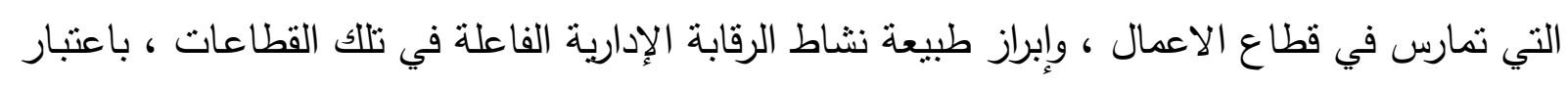

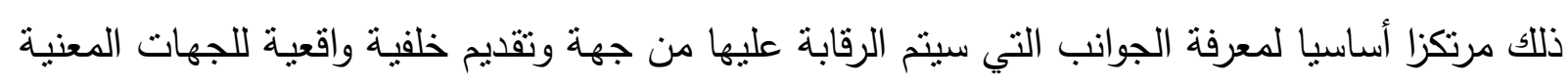

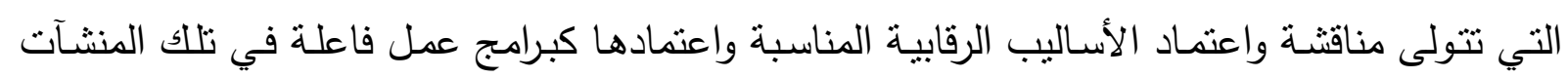

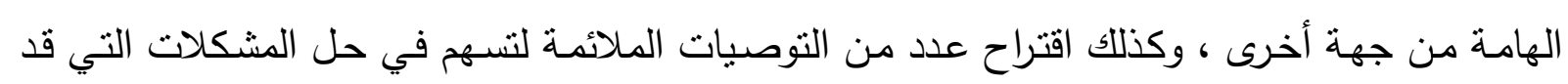

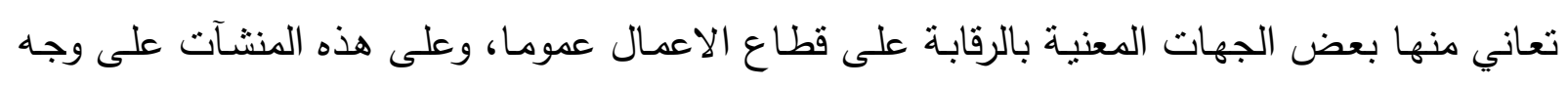
الخصوص .

\section{مشكلة الاراسة:}

تعتبر انشطة قطاع الاعمال لها دورا كبير ومؤثر في اقتصاد أي بلد مهما كانت مرحلة النطور

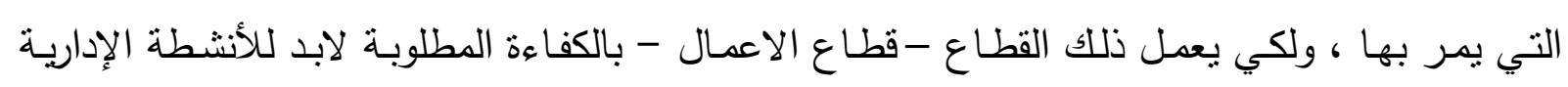

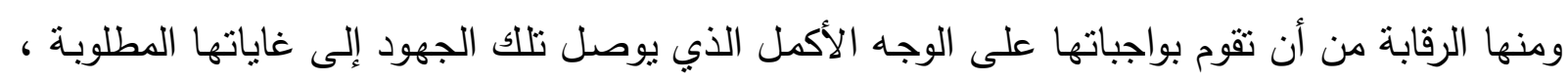

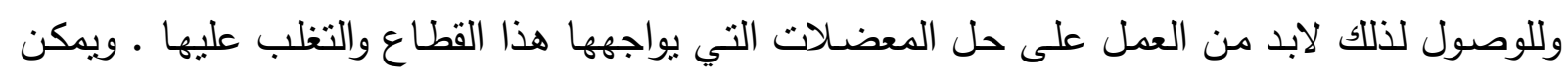

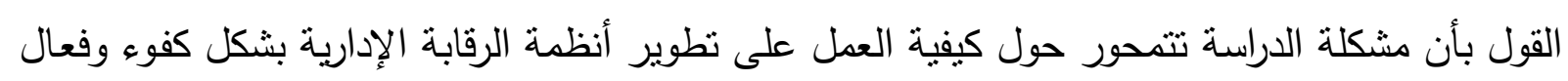

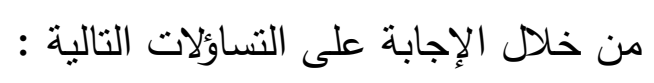

- ما هي المقومات الأساسية اللازمة لتحقيق عملية الرقابة في قطاع الإلية الاعمال.

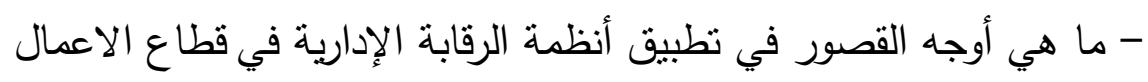

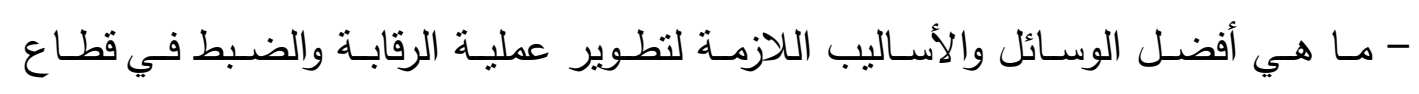
الاعمال. 


\section{فرضيات الاراسة :}

يمكن صياغة فرضيات الدراسة على النحو النالي :

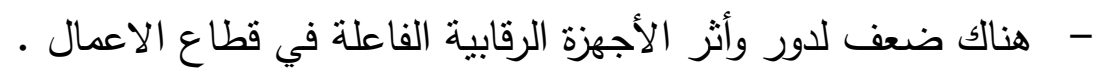

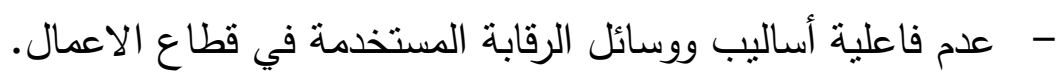

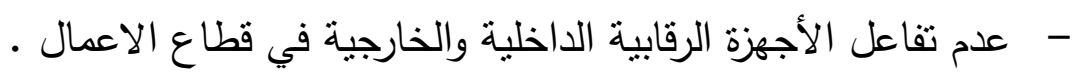

\section{مجتمع الدراسة وعينتها :}

يتكون مجتمع الدراسة من جميع الأفراد العاملين في قطاع الاعمال ممن يشغلون وظائف متتوعة مع التركيز على العاملين في الثؤون الإدارية ، حيث بلغ عدد مجتمع الدراسة بآه فرد ، وقد استخدت

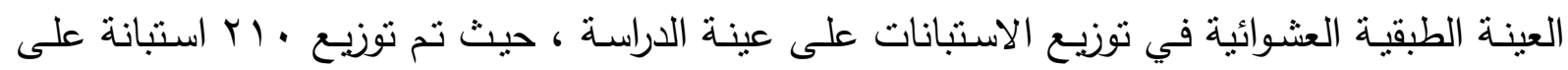

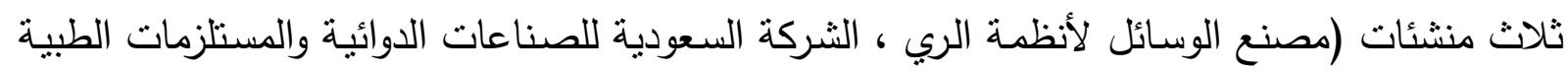

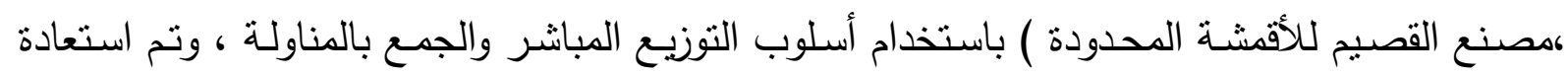

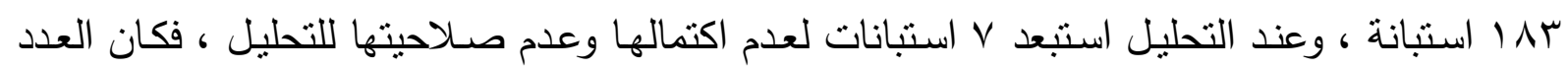

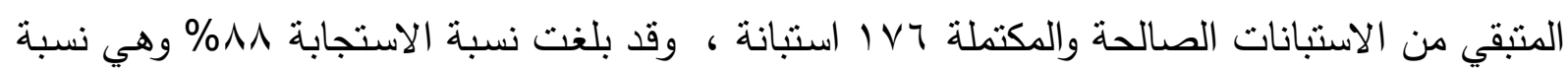

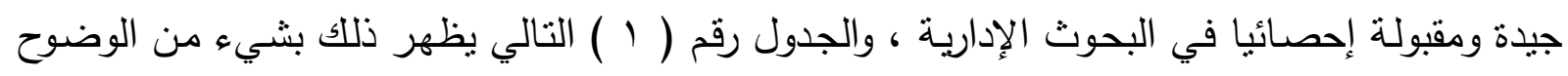
والتفصيل .

$$
\text { جدول رقم ( ) ( ) }
$$

الاستبانات الموزعة في البنوك المستهدفة وتفصيلاتها

\begin{tabular}{|c|c|c|c|c|}
\hline الصالح & الغير صالح & عدد الفاقد & عدد الاسنبانات الموزعة & اسم البنك \\
\hline$\pi$ & 1 & $\varepsilon$ & TV & مصنع الوسائل لأنظمة الري \\
\hline OV & r & $\wedge$ & TV & 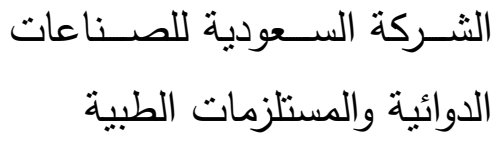 \\
\hline ov & $\varepsilon$ & 。 & 77 & مصدــــنع القصـــــم للأقمشـــــة \\
\hline IVT & V & iv & Y). & المجموع \\
\hline
\end{tabular}




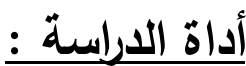

استخدمت الاستبانة كأداة للاراسة وقد تكونت هذه الأداة من جزأين اشتمل الجزء الأول منها على العوامل

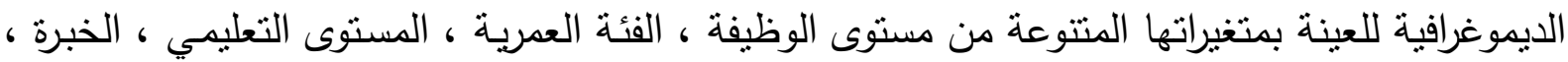

$$
\text { مدة العمل في الموقع لحالي ، وكما يظهر في الجدول رقم ( r ) ل }
$$

بينما تضمن الجزء الثاني منها على أسئلة قدمت للعينة تغطي محاور الدراسة وفرضياتها ، وقد تضمنت الاستبانة على ثلاثا وثلاثين فقرة ، وطلب من العينة المستهدفة الإجابة على فقراتها ضمن مقياس ليكرت

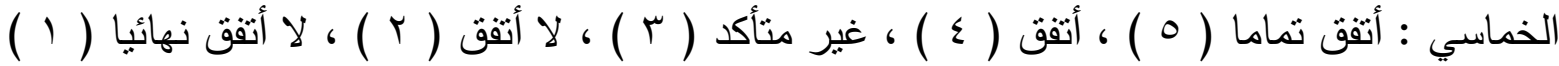

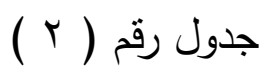

\begin{tabular}{|c|c|c|c|}
\hline النسبة & العدد الع & الفئة & المتغير \\
\hline$\varepsilon, r$ & 7 & مدير عام & الوظيفة \\
\hline r. & 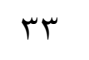 & رئيس قسم & \\
\hline$v 7,7$ & 1ro & مستويات أخرى & \\
\hline$\varepsilon \wedge, r$ & 10 & . r - مب سنة & 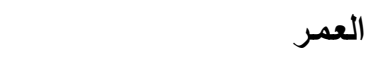 \\
\hline$r \varepsilon, 1$ & 7. & צr - 0ء سنة & \\
\hline $1 V, T$ & r & أكبر من ؛ سنة & \\
\hline $1 \cdot, r$ & 11 & ثانوية عامة & المستوى التعليمي \\
\hline $9, \vee$ & iv & دبلوم & \\
\hline $7 \cdot, r$ & 1.7 & بكالوريوس & \\
\hline $1 \cdot, 1$ & 19 & دبلوم عالي & \\
\hline $7, r$ & 11 & ماجستير & \\
\hline$r, \Lambda$ & 0 & دكتوراه & \\
\hline$\varepsilon r, r$ & vo & أقل من 7 سنوات & سنوات الخدمة (الخبرة ) \\
\hline$r,, 1$ & rq & $1 \cdot-7$ & \\
\hline$r \cdot, 0$ & ru & $10-11$ & \\
\hline $1 \cdot, 1$ & 19 & $r \cdot-17$ & \\
\hline$\varepsilon$ & v & أكثر من • r سنة & \\
\hline $7 \cdot, \Lambda$ & $1 \cdot v$ & أقل من ץ سنوات & مــــة العــل فـــ المنصـــب \\
\hline$r 9,0$ & or & r & \\
\hline $9, \vee$ & iv & أكثر من 7 سنوات & \\
\hline
\end{tabular}

توزيع أفراد العينة حسب العوامل الديموغرافية 


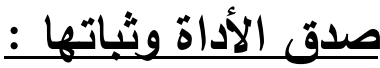

يقصد بصدق الأداة ، قدرة الاستبانة على قياس المتغيرات التي صمدت الاستبانة لقياسها ، وعلى هذا الأساس تم عرض الاستبانة على عدد من الأكاديميين والمتخصصين في الدراسات الإدارية وضمن المجـال العلمي والعملي للاراسـة لمراجعة المتغيرات كافـة ، وقدرة الفقرات على تغطيـة محساور الدراسـة واثباعها ، وقد تم الاستفادة من المقترحات ، والتعديل بناء على ملاحظات وآراء المحكمين . أمسا ثبات الأداة ، فيقصد بـه مدى الحصول على النتائج نفسها لو كررت الدراسـة في ظروف منـابهة

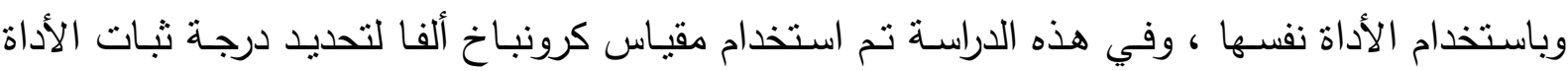

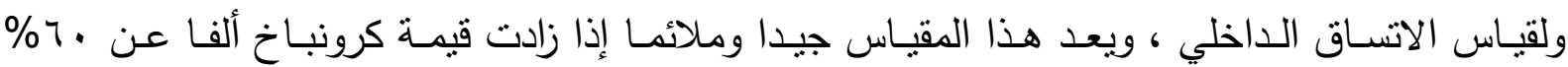
وبالتالي تكون مقبولة ، وعند تطبيق هذا الاختبار على الدراسة وجد أن قيمة ألفا لجميع متغيرات الاستبانة

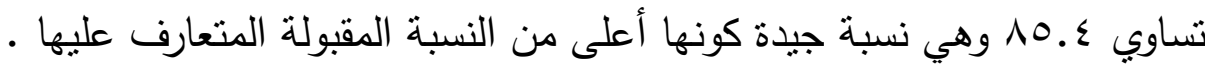

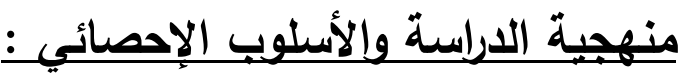

اعتمد الباحث في دراسته على المنهج الوصفي التحليلي حيث تمت مناقتشة بعضا من الآراء العلمية

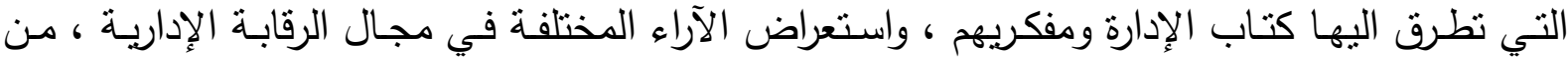
خلال المراجع العلمية التي أمكن الوقوف عليها ، كذلك تم الاتثقال إلى التحليل الاستقرائي للاراسة العملية واختبار الفروض المتعلقة بجوانب الدراسة ، بهدف إبراز الجوانب الإيجابية فيها والعمل على تطويرها وبما يتلاءم وخصوصية العمل في قطاع الاعمال. ولغرض استخلاص النتائج مـن البيانـات التي جمعت ، تم الاستعانة بالحاسب الآلي عبر البرنـامج

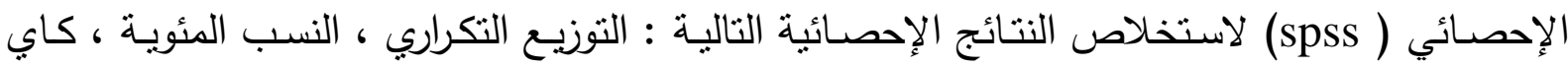

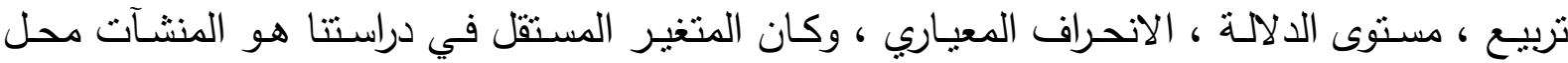

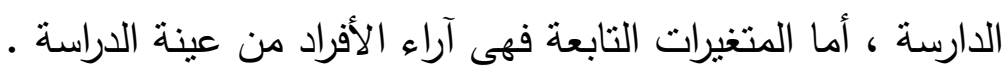

\section{حدود الدراسة : مانة}

الحدود المكانية : اقتصرت الدراسة على بعض مؤسسات وشركات قطاع الاعمال في القصيم (مصنع الوسائل لأنظمة الري ، الثركة السعودية للصناعات الدوائية والمستلزمات الطبية ،هصنع القصيم للأقششة المحدودة ) في مدينة بريدة والتي تعتبر مركز محافظة القصيم .

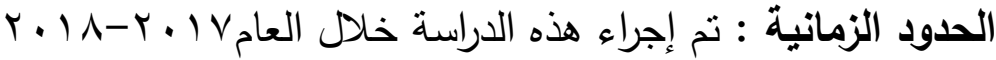




\section{الاراسات السابقة :}

حاول الباحث الوصول إلى أكبر عدد ممكن من الدراسات السابقة القريبة من هذه الدراسة والتي أمكن

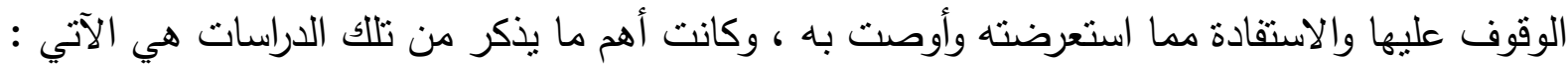
- دراسة محمد (10 ب ب) بعنوان " الرقابة الادارية واثرها على الاداء "دراسة حالة، هيئة الكوانئ البحرية في السودان ، تهدف الدراسة الى معرفة اسباب القصور في اداء القوى التى الداء البشرية والمعدات التي يؤدى بها العمل وتحديد الصعوبات التي تواجه الادرة في عملية الرقابة، ولقد نوصلت الدراسة الى ان الكوادر الادارية مؤهلة علميا ومدربة ندريبا عمليا مع وجود ادوات وآلية للرقابة ، كما انه لا يوجد تساهل في عملية تطبيق الرقابة الادارية

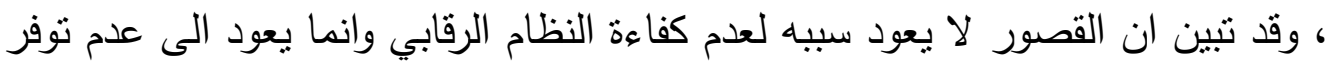
الرضى الوظيفي لاى العاملين بسبب حرمانهم من الترقيات وشعور العاملين بعدم المساواة بصرف المكافئات وفرص التدريب الخارجي، ولقد اوصت الدراسة بضرورة تحقيق مبدأ المساواة بين العاملين في المكافآت وفرص التدريب والترقيات واجراء تتقلات بين الاقسام المختلفة لإكساب العاملين مزيد من المعارف والخبرات المختلفة .

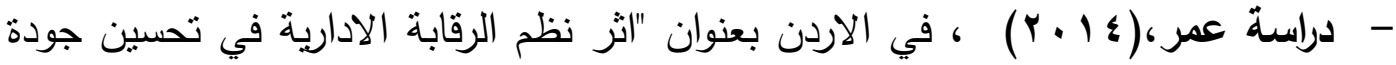

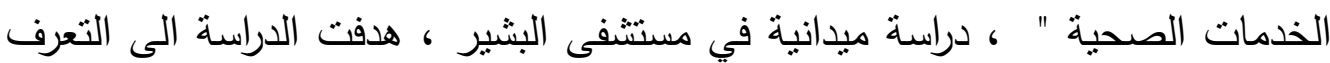
على اثر الرقابة الادارية في تحسين جودة الخدمات الصحية في مستشفى البشير بعمان

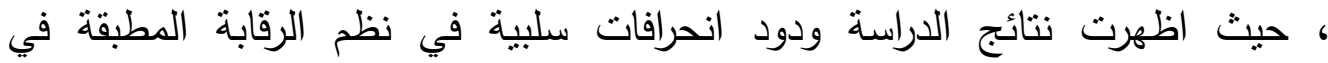
المستشفى ونظام الحوافز ونظام تقييم الاداء ونظام الرواتب ، بالإضافة لضعف الادوات الرقابية الموجودة بالمستشفى ، الدراسة الى ضرورة نطوير نظام رقابي حديث لتحقيق

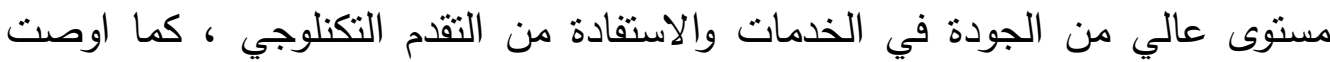
ببناء ثقة تتظيمية مؤسسية لإكساب العاملين القيم والعادات السلوكية الحميدة لكي تعمل كأدوات رقابية ذاتية على ادائهم وتطبيق نظام السمعة في نقييم اداء العاملين.

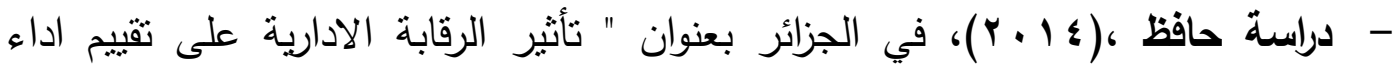

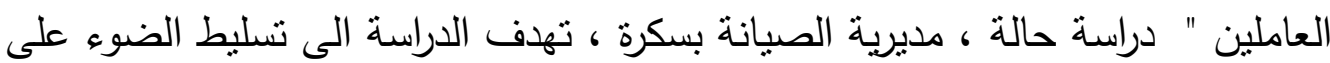
الرقابة الادارية ونقييم العاملين والسعي لتحديد العلاقة بين الرقابة الادارية واداء العاملين ومعرفة وفهم واقع الرقابة الادارية بمديرية الصيانة بسكرة ـ وتوصلت الدراسة الى وجود علاقة ايجابية بين الرقابة الادارية وتقيم اداء العاملين كما ان الرقابة الادارية تساعد على لعى لاديه

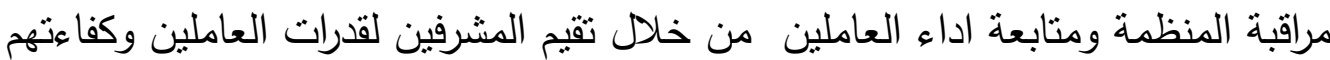
مما يؤدي الى زيادة اداء وتحقيق اهداف المنظمة . 


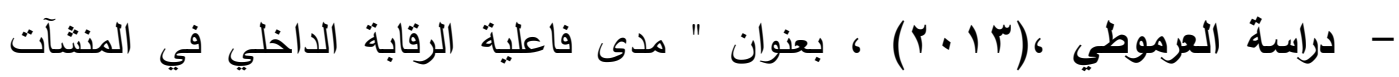

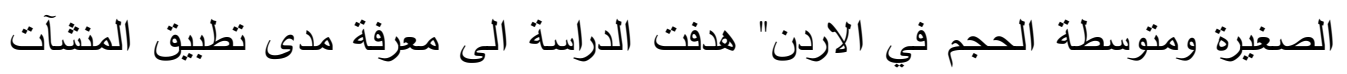

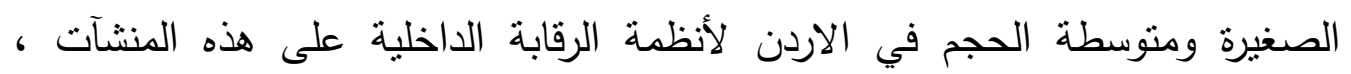

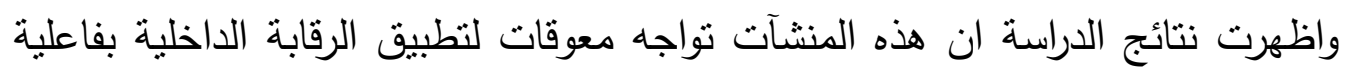
تمنتل بضعف انظمة الرقابة الداخلية المطبقة فيها ، وعدم التزام هذه المنشآت بنطبيق

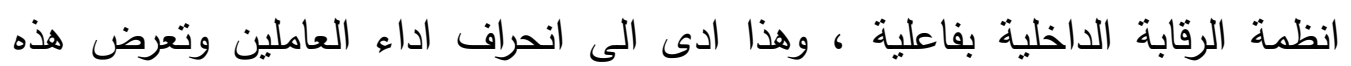
المنشآت للخسائر المستقبلية ، واوصت الدراسة بضرورة قيام الجهات الرقابية والتشريعية التهاتية بتطوير النتريعات والقوانين التي من شانها ان تزيد من التزام هذه المنشآت بتطبيق انظمة الرقابة الداخلية بفاعلية .

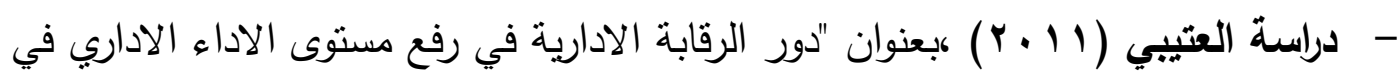

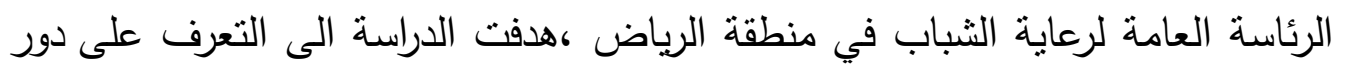

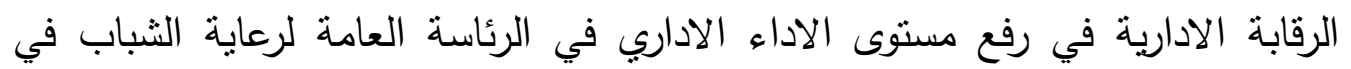

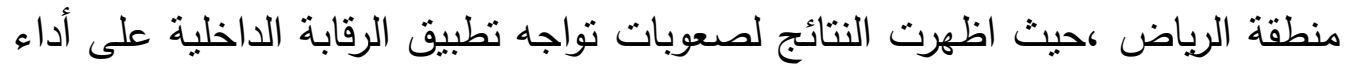
العاملين في الرئاسة العامة لرعاية الثباب ، مما ادى الى تراجع في اداء العاملين ، بالإضافة الى ضعف التدريب للرؤساء في مجال الرقابة ـ ـواوصت الدراسة بضرورة

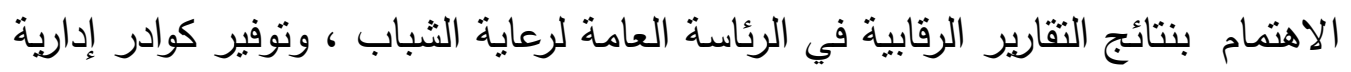

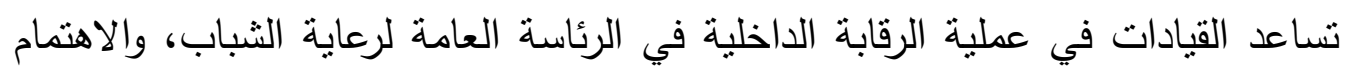

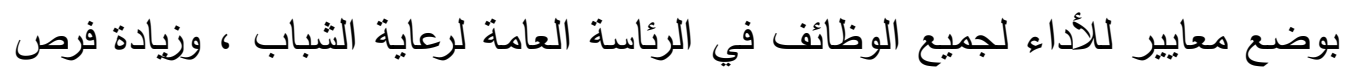
التدريب في مجال الرقابة الداخلية للرؤساء في الرئاسة العامة لرعاية الثباب.

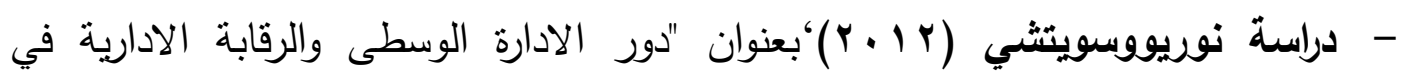

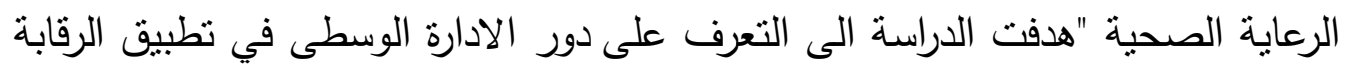

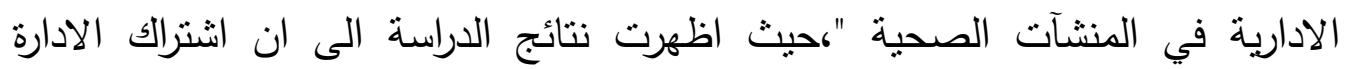

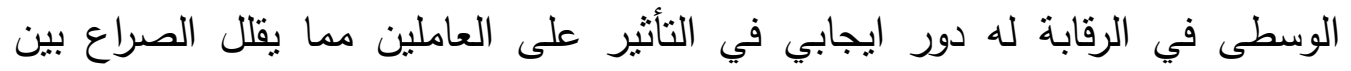
العاملين والمنظمة ، وتحقيق الرضا الوظيفي للعاملين ويساعد الى خلق التفاعل بين

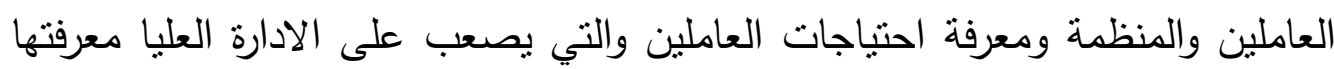

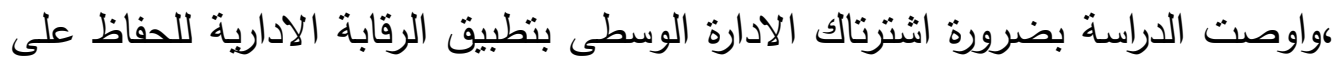
جودة عالية في الخدمات ولتحقيق السيطرة على النشطة الدختلفة بين الدستويات الادارية المختلفة . المهان

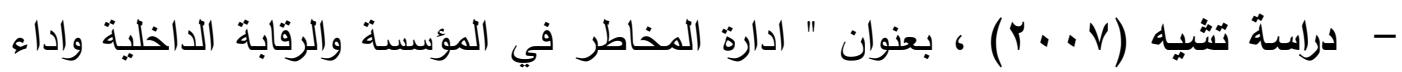

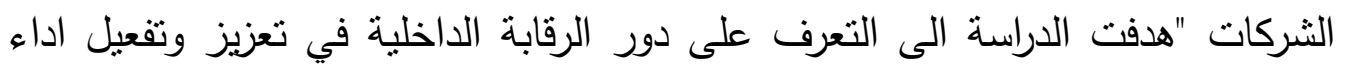


الثركات وفي تقليل المخاطر التي تتعرض لها ، حيث اظهرت نتائج الدراسة وجود قصور في اداء العاملين وضعف للى الثركات التي تفقتر الى انظمة الرقابة الداخلية

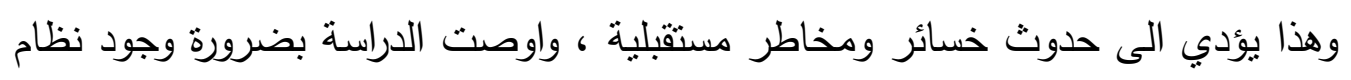

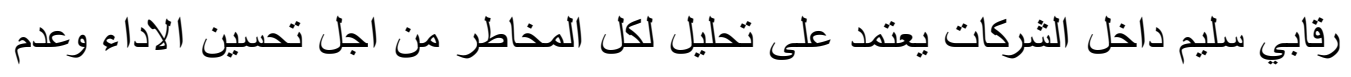

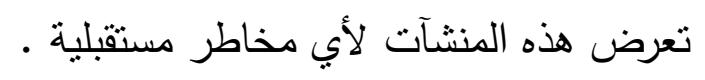

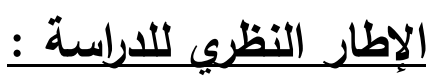

تعتبر الرقابة الادارية الوظيفة النهائية في سلسلة الوظائف الإدارية (التخطيط ، التنظيم، التوجيه

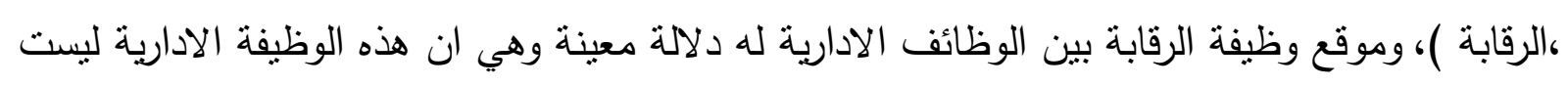

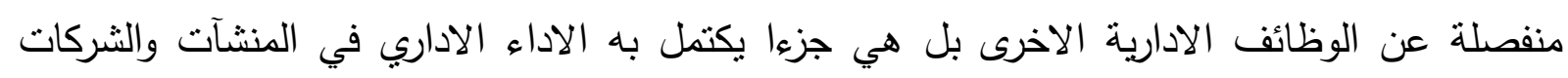

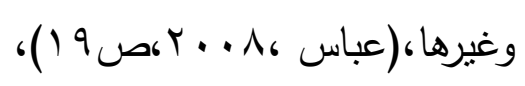

والرقابة هي الخطوة الأخيرة بين مراحل العمل الأساسي للمدير ، بل تعد الرقابة من المهام الرئيسية

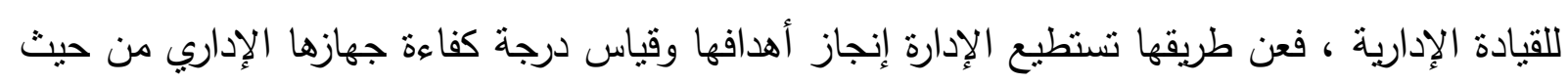

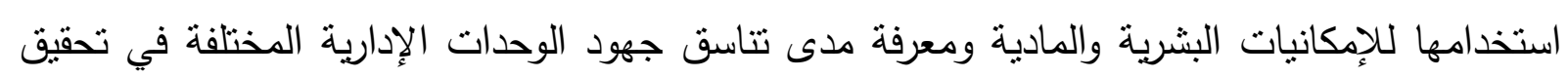

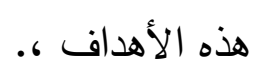

وتعتبر الرقابة من الوظائف الحيوية في الدول الحديثة التي تعطى كل الاهتمام ، فالرقابة لا تمارس في

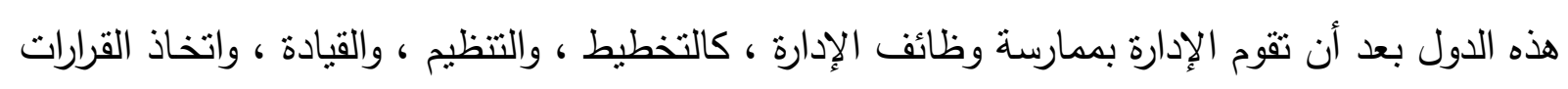

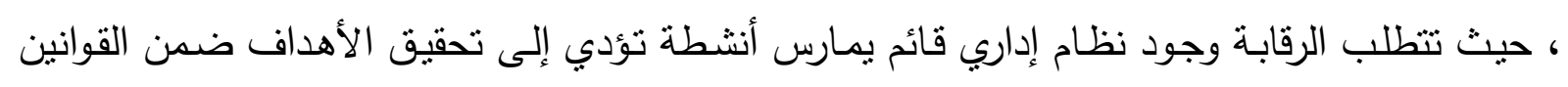

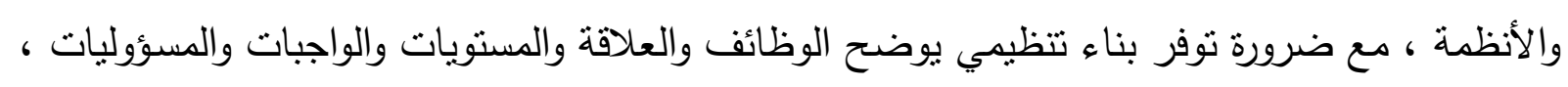
وكذلك العلاقة بينها وبين المستويات والواجبات الأخرى ، ونتيجة لأهمية ودور الرقابة الإدارية في تحقيق لإنيق

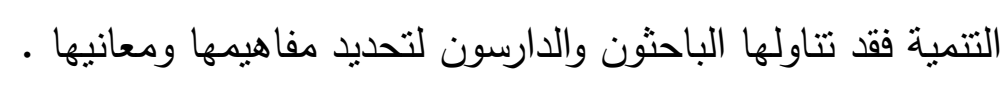

\section{مفهوم العملية الرقابية}

تمثل الرقابة الادارية تلك العملية المنظمة المتعلقة بالتحقق والتأكد من اتمام الانشطة والالتزام بالأعمال

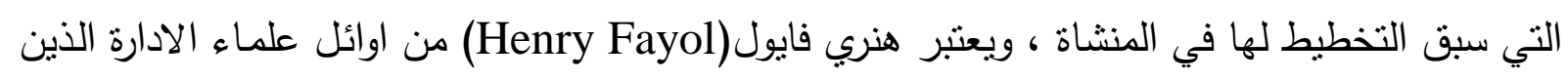

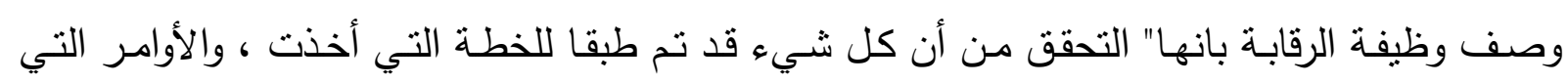

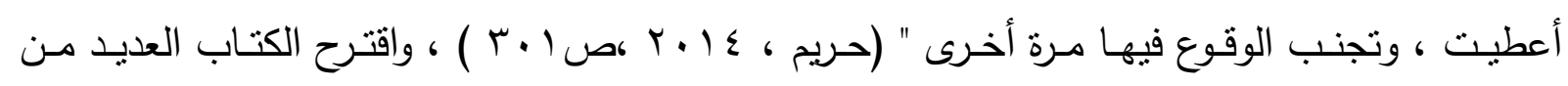

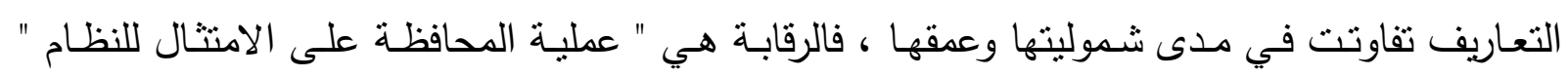

( Ivancevich,1999,p390) 
ويرى محمود بان الرقابة هي " تلك الوظيفة الادارية المسؤولة عن التأكد من جعل الاثشياء تحدث كما

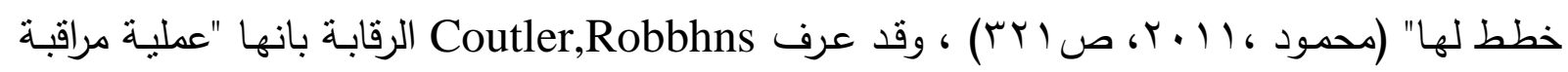

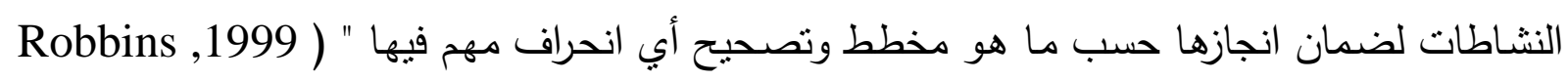

وهنالك مفهوم حديث نسبيا يجدر التطرق إليه في هذا المجال وهو مفهوم الرقابة بالاستثناء وبناء على هذا

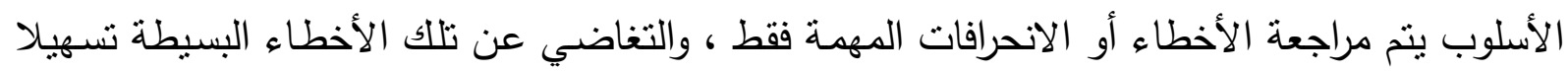

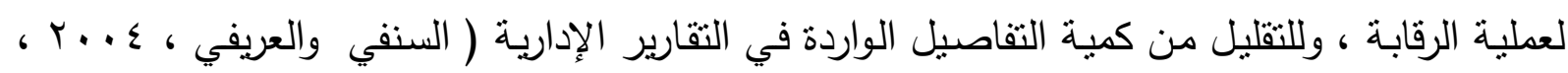

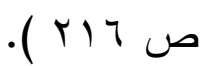
يلاحظ من التعاريف السابقة أن الرقابة تتضمن وجود أهداف محددة حتى تكون وسيلة بستطيع بواسطتها

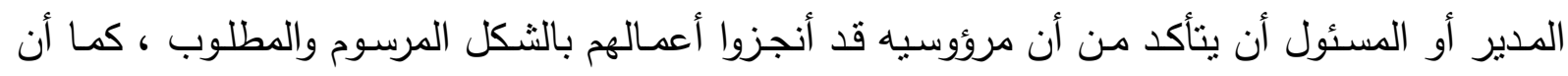

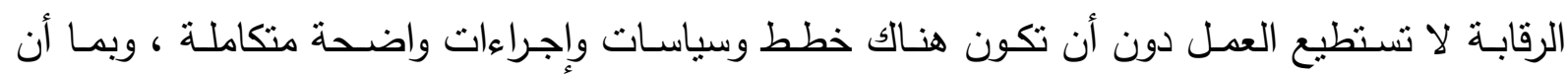

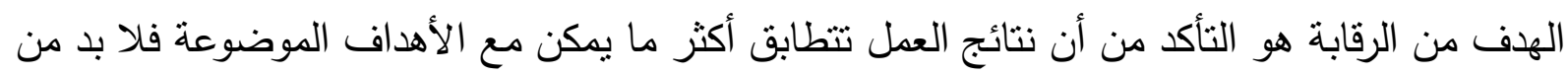

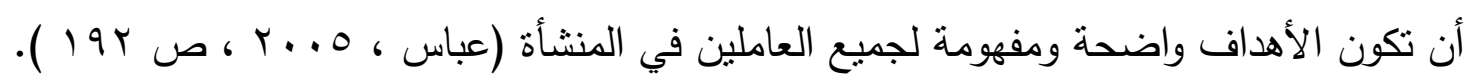

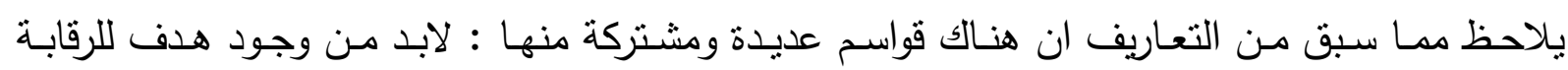

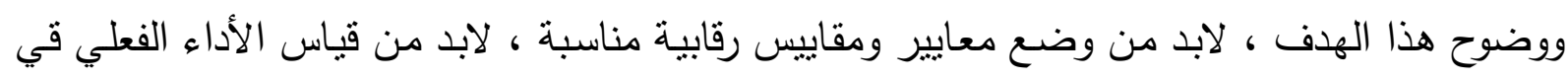

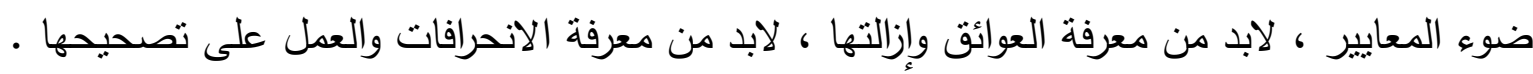

\section{أغراض واهداف الرقابة الإدارية}

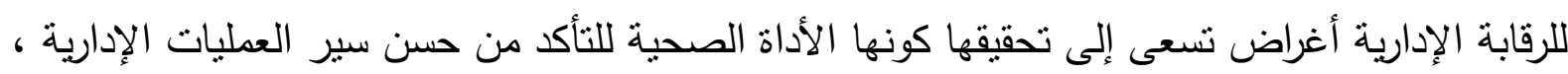

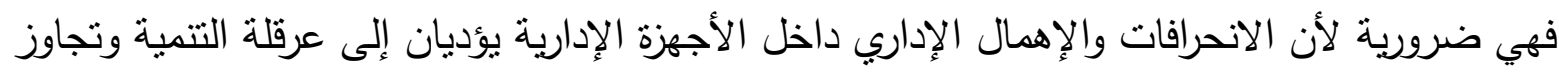

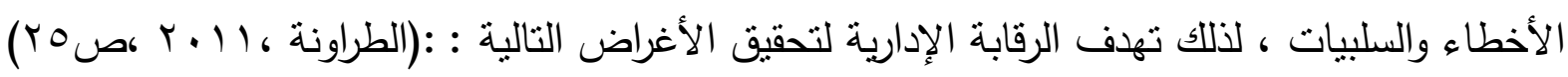

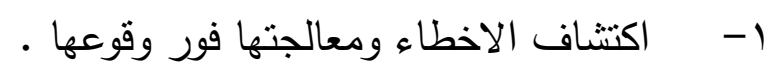

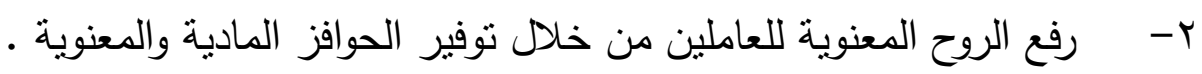

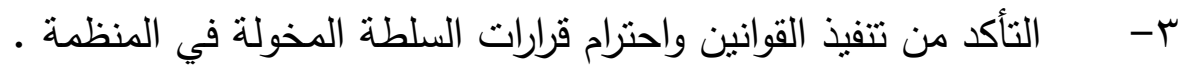

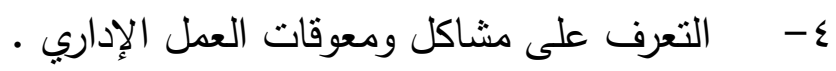

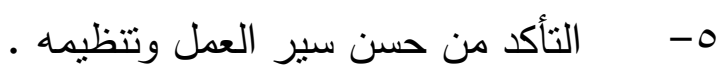

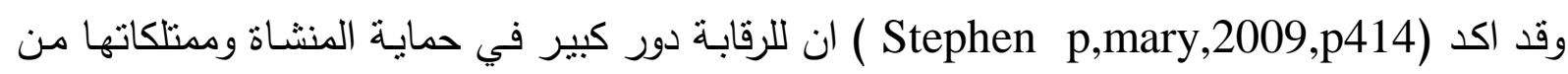
المخاطر والتهديدات التي قد تتعرض لها ، كما تساعد العاملين في الحصول على معلومات عن عن ادائهم مما يمنع تكرار الاخطاء في العمل . 
للعملية الرقابية مراحل وخطوات لابد للقائمين عليها من تتبعها بحسب تسلسلها حتى تصل لأغراضهـا

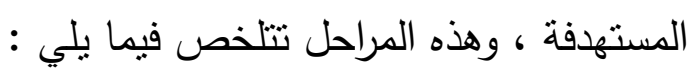
المرحلة الأولى : بناء المعايير: وهي تمثل النتائج المطلوبة ، والمعيار هو أداة قياس كمية أو نوعية ينت

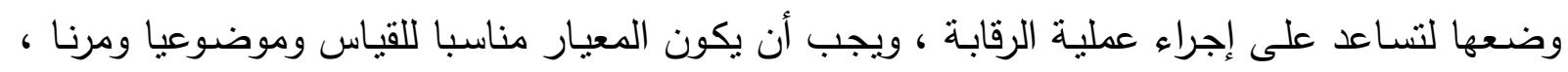

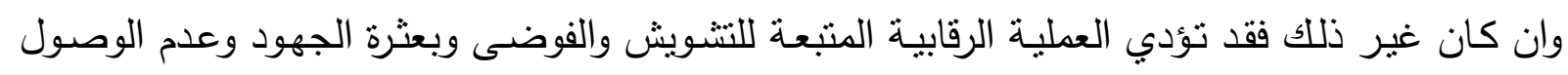

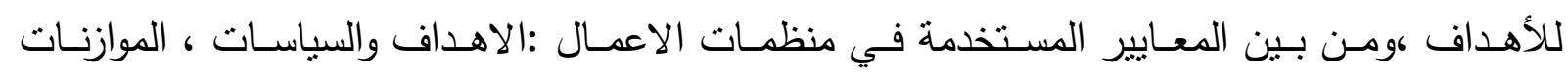

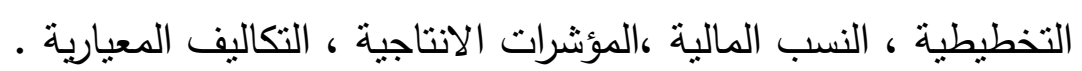

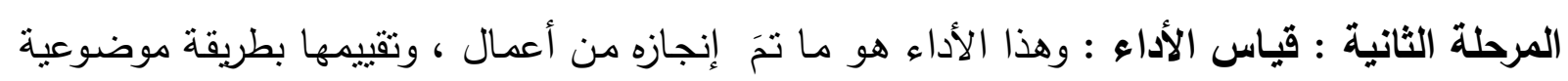

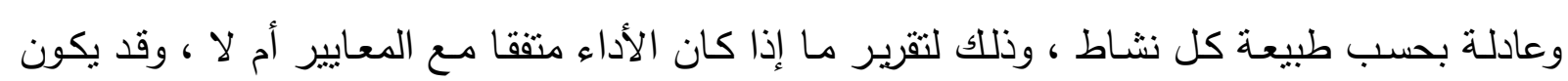

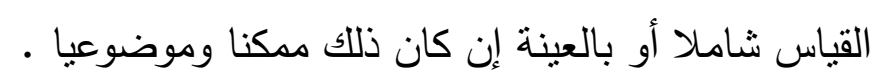

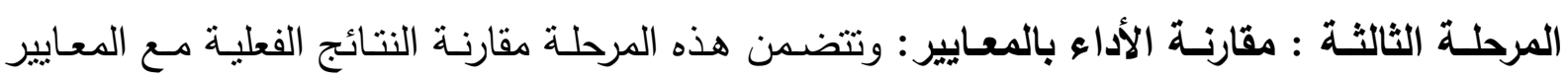

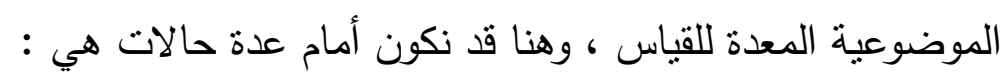

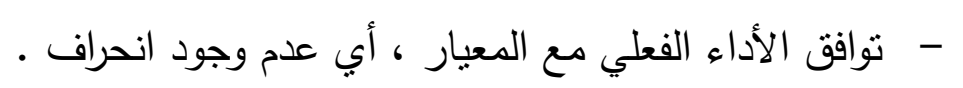

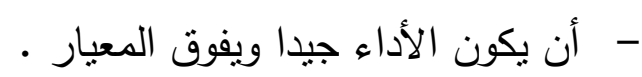

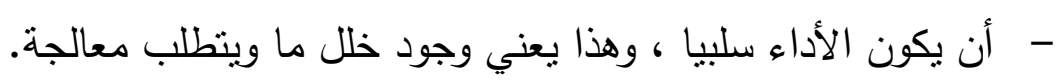
المرحلة الرابعة : اتخاذ الاجراءات المناسبة :وهي تتضمن تحليل الانحرافات بين النتائج الفعلية وبين

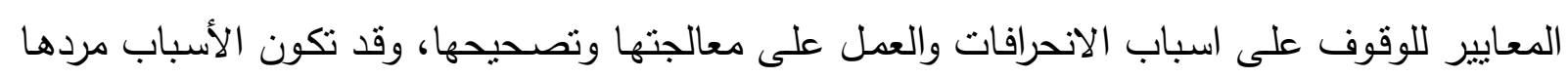

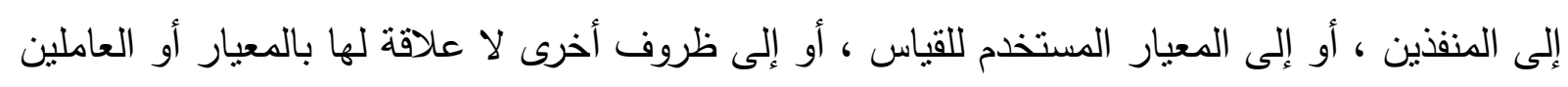

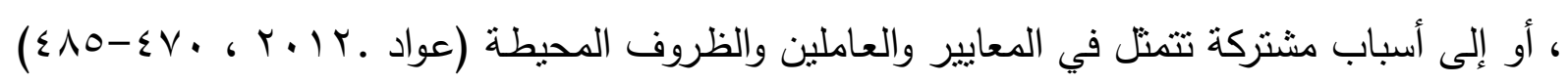

وفي كل الحالات والأحوال فان العمل الرقابي هو شأن إداري منظم ومخطط ، وهو يمر بمراحل متتابعة

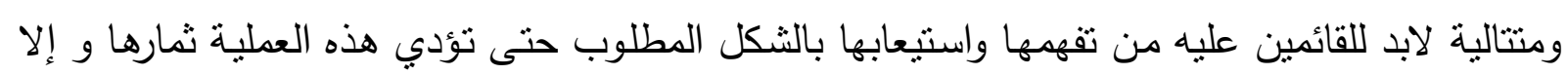
أضحت مضيعة للوقت ومعيقة للعمل . 


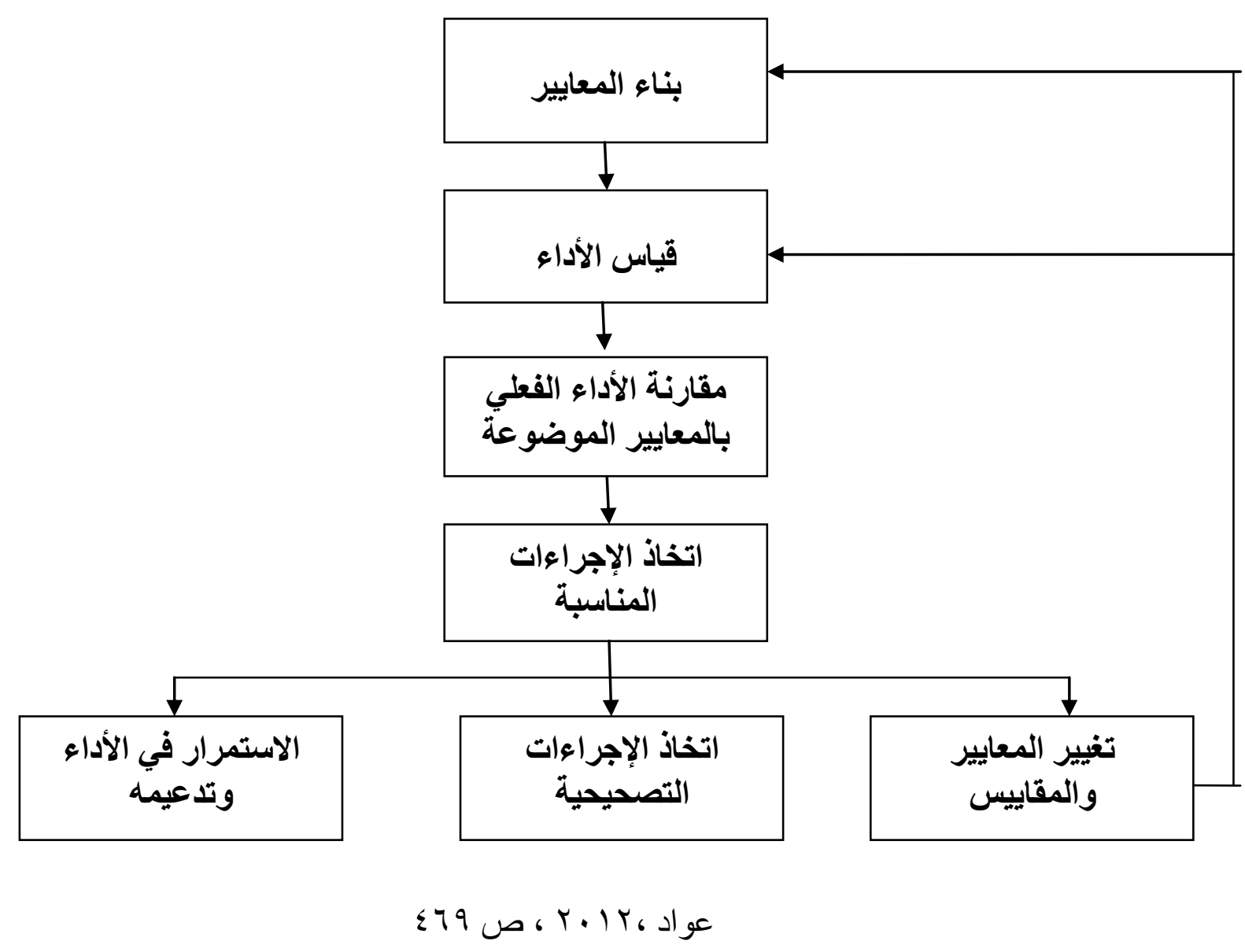

فوائد الرقابة واستخذاماتها

بمكن استعراض اهم فوائد واستخدامات الرقابة الإدارية ، وتتمثل في : 1- تتميط الاداء وزيادة كفاءة المنظمة وتقليص النفقات .

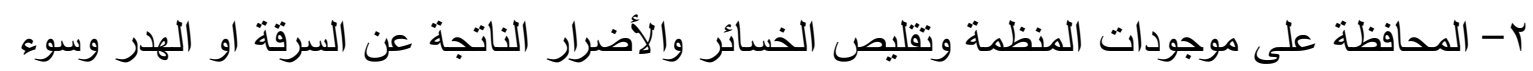

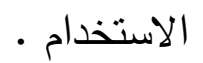

ب- تتميط الجودة وتلبية احتياجات مصممي المنتجات في المنظمة .

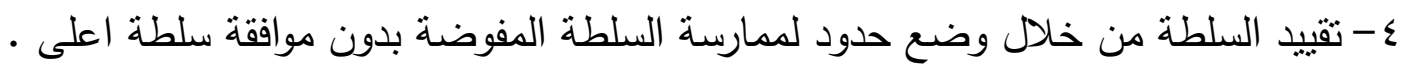
0- قياس الاداء اثثاء تنفيذ العمل من خلا وضع اساليب لقياس الاداء .

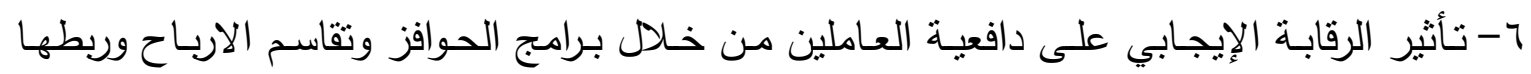

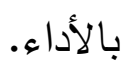

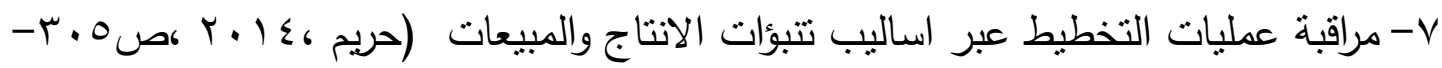
$(r \cdot T$ 


\section{أساليب الرقابة الإدارية}

للرقابة الإدارية عدة أساليب يتم من خلالها تطبيق الرقابة ، وهذه الأساليب تتمنل في : 1 - التقارير الإدارية : وهي تعتبر من أكثر الأساليب فعالية بسبب إعطائها صورة واضحة عن كيفية إنجاز الأعمال ومدى كفاءتها وتطابقها مـع الخطط المرسومة ، إضـافة إلى دقتها وتحقيقها للتتسيق بين الإدارات والأقسام ، وتعتمد كفاءتها على لغتها السليمة وتعابيرها الإنشائية وإتباعها القواعد العلمية المتبعة في كتابـة التقارير ، كما يعزز فاعلية التقارير ما تتضمنه من بيانات ومعلومات إحصائية

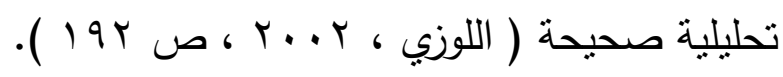

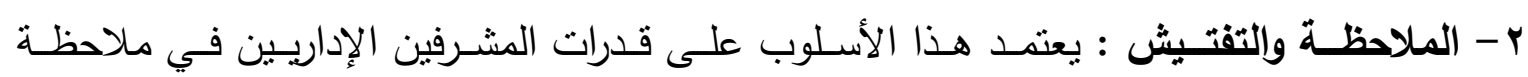
المرؤوسين أثثاء قيامه بأداء أعمالهم ، وأيضا ملاحظة الطرق والأساليب والنتائج التي يتوصل إليها المرؤوسون أثناء سير العمل ، كما يتضمن هذا الأسلوب إضافة إلى الملاحظة القيام بعمليات فحص بله

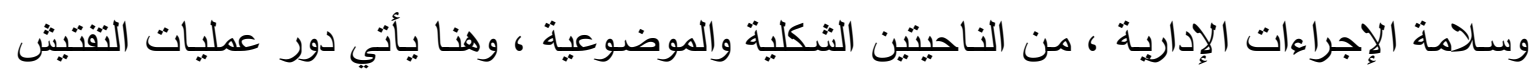
من خلال فحص الوثائق والسجلات والأوراق الرسمية وغير الرسمية ، وأحيانا يكون الأسلوب المتبع

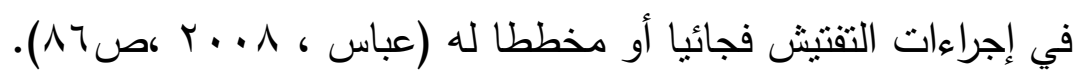

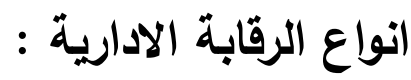

هناك انواع مختلفة ومتتوعة من الرقابة بمكن للإدارة استخدامها ، وهي كما يلي : ا-توقيت تطبيق وممارسة الرقابة : وتصنف على هذا الاساس الى :

- رقابة وقائية (سابقة) : وتهدف الى منع أي انحرافات يمكن ان تحدث في تتقيذ خطة المنشـاة ، فهي تتظم ونضبط جودة وكمية الموارد قبل تحويلها إلى مخرجات. - - الرقابة المتزامنة ( الانية ) : ويطلق عليها بالعلاجية ، وتتم فيها مراقبة العمليات الجارية لضمان تحقيق الاهداف المعتمدة ، وهي موجه لمراقبة عمليات تحويل المدخلات الى مخرجات . - - الرقابة اللاحقة :وهي تتم بعدا تمام العمل ومقارنتها بالمعايير المعتمدة مسبقا وهي تركز على المخرجات

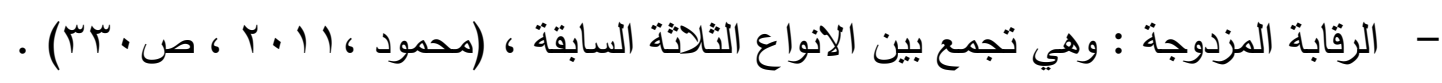
r - من حيث مصدر الرقابة : وتصنف الى : - الرقابـة الداخليـة : تســى بالمراجعـة الداخليـة بحيـث يقوم كـل مـدير او رئسيس بمراقبـة انثـطة وعمليات الوحدة التنظيمية التي يشرف عليها ـ التئ.

- الرقابة الخارجية: وتقوم جهة من خارج المنشاة بتقييم ومراجعة عمليات المنشاة ومستوى ادائها ـ r- الرقابة من حيث مدى تكرارها وإنتظامها : وتصنف ابه الى : 


$$
\text { - - رقابة دورية - رقابة مفابية او عرضية . }
$$

\begin{tabular}{|c|c|}
\hline التقسيم & الأساس \\
\hline 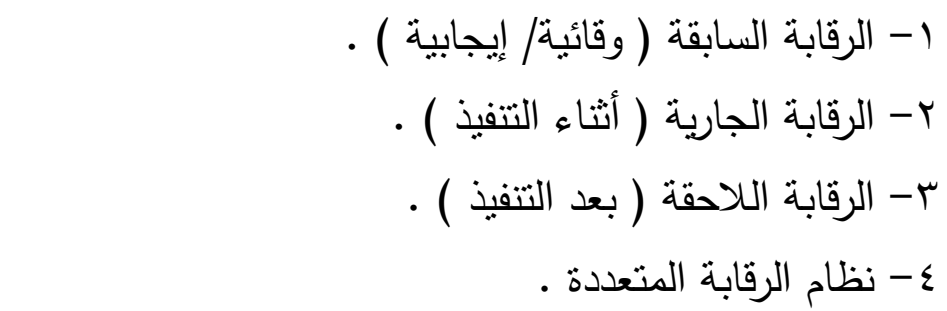 & الزمــن \\
\hline r- الرقابة الداخلية ( قسم ضمن الهيكل التنظيمي للمنظمة ) . & 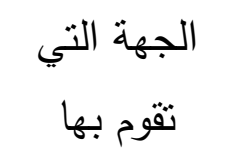 \\
\hline r- r- الرقابة الرقابة الدورية . الرفئة . & التظظيم الرقابي \\
\hline
\end{tabular}

جدول رقم ( 1 ) انواع وأصناف الرقابة الادارية

\section{الرقابة الإدارية والفكر الإداري المعاصر}

ظهور الأنماط الإدارية الجديدة نتيجة للتحولات والتغيرات والانفتاح العالمي يتطلب من الإدارة

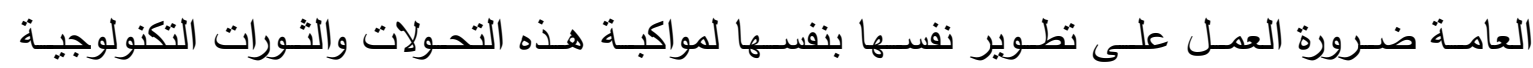

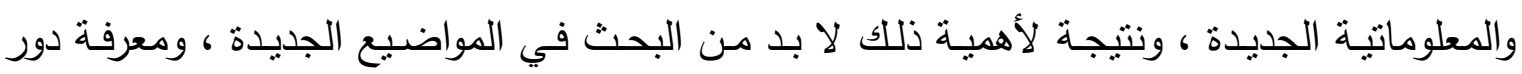

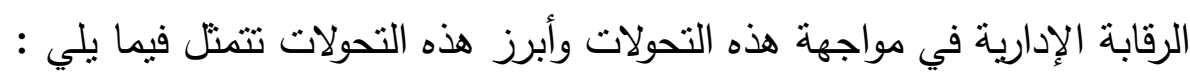

1- الرقابة والخصخصة

إن لهذا المفهوم الجديد في إدارة النشاطات معنى آخر ودورا نشيطا في تفعيل العملية الرقابية ، فمن حيث المعنى تعني الخصخصة تتشيط دور القطاع الخاص وتوسيعه حتى يغطي معظم النشاطات الاقتصادية ، فتفعيل دور هذا القطاع يعني زيادة الأنثطة الرقابية على المشروعات ومحاولة تصحيح الانحرافات ومعالجة التخلف الإداري وتحسين كفاءة المؤسسات الإنتاجية .

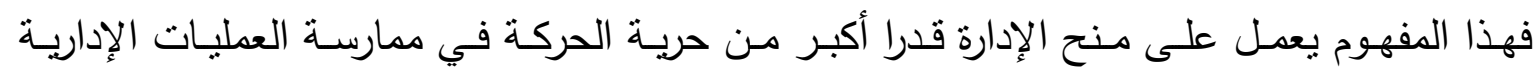

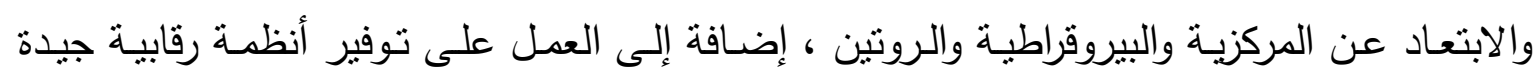


ومساءلة جادة ، كما تسمح الخصخصة بإقامة هيئات رقابية تمارس عملها على التظظيمات الإدارية

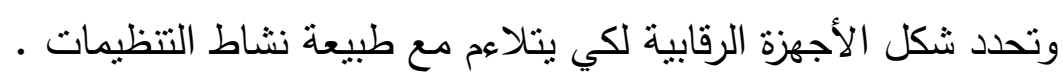

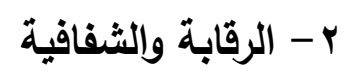

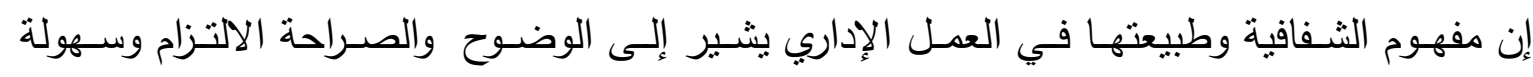

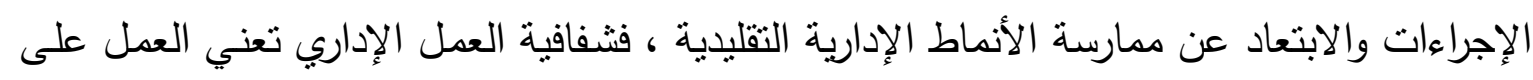

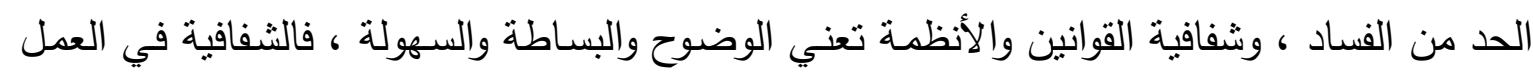

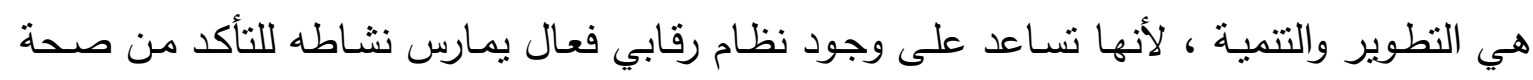

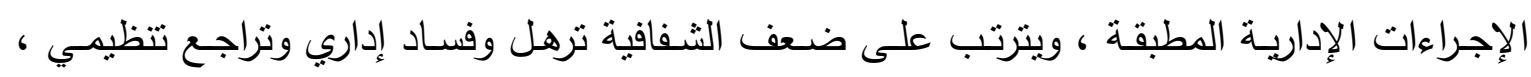

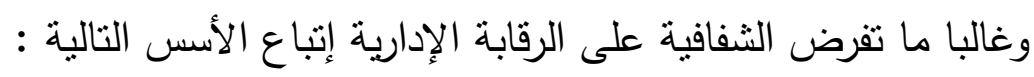

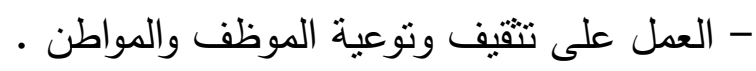
- الاهتمام بالأفراد المتميزين وإبراز حالات النجاح والإبداع ، وكذللك إبراز حالات التراجع حتى ينت

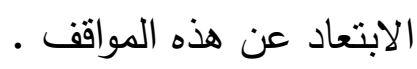

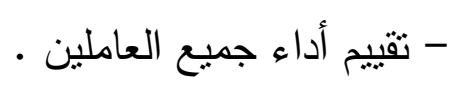

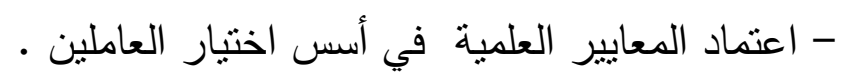
- التأكيد على الرقابة والمساءلة . - جعل التزقيات مبينة على أساس الكفاءة . - توفير آلية واضحة وسهلة للموظف للشكوى والنظلا . - تنظيم لقاء دوري منتظم للأجزة المركزية المعينة بالرقابة والإدارة .

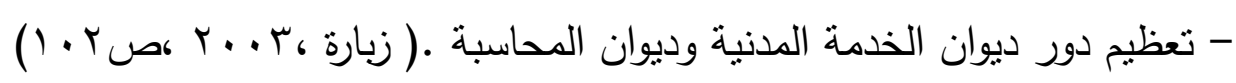

\section{خصائص النظام الرقابي الفعال :}

لكي يحقق نظام الرقابة دوره في تمكين المنظمة من تحقيق اهدافها بكفاءة فانه لابد من توافر بعض

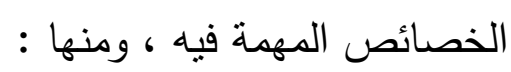

1- ملاءمة النظام الرقابي مـع طبيعة وحجم النشاط :لا يتحقق نجاح اي نظام للرقابة الا اذا اتسم

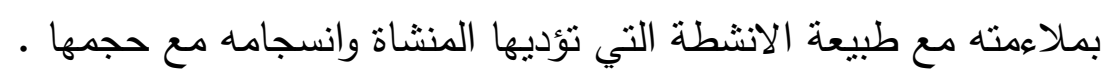

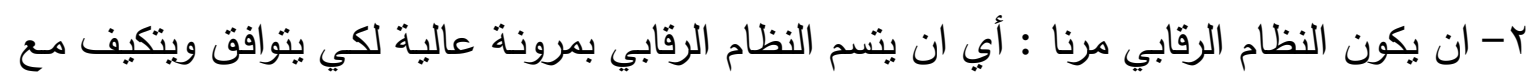

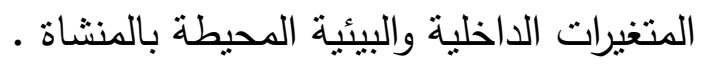
r- ان ينسم النظام الرقابي بالوضوح وسهولة الفهم :من قبل جميع المسؤولين عن تطبيق هذا النظام

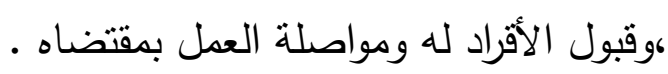




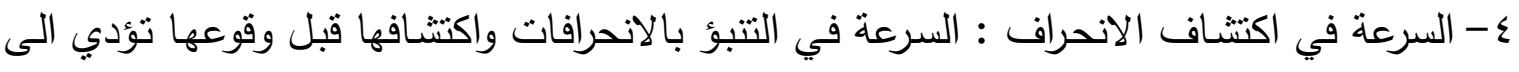

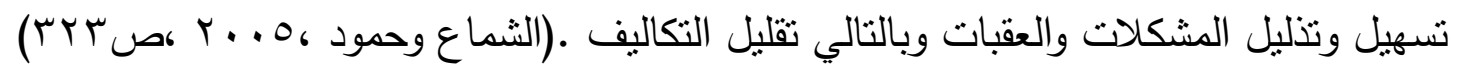

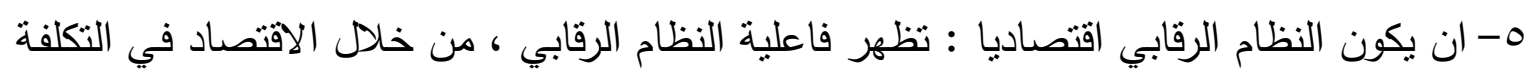
، بحيث تكون المردودات المتحققة أكبر من تكاليف نظام الرقابة .

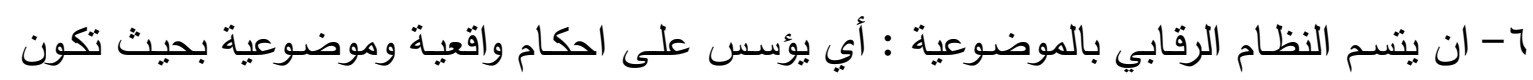

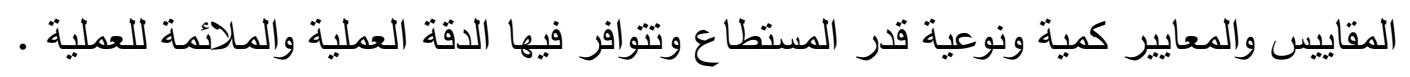
V- ان يكون النظام الرقابي تصحيحيا وليس عقابيا فقط : الرقابة ليست لتصيد اخطاء العاملين وانزال

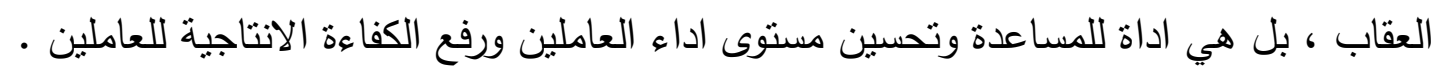

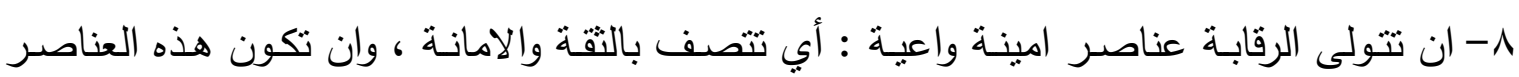

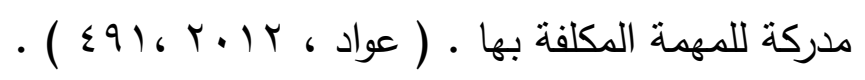

\section{العنصر الإنساني في الرقابة}

يرى العديد من مفكري الإدارة أن الهدف من عملية الرقابة الإدارية هو أحداث تغيير في سلوك الأفراد

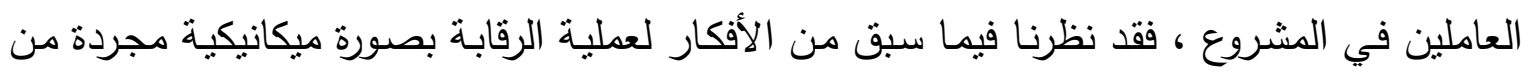

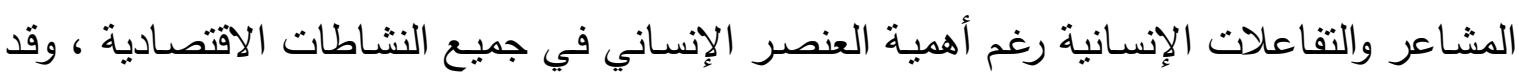

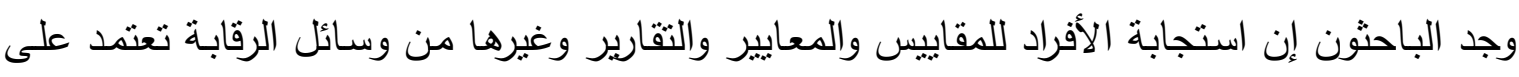

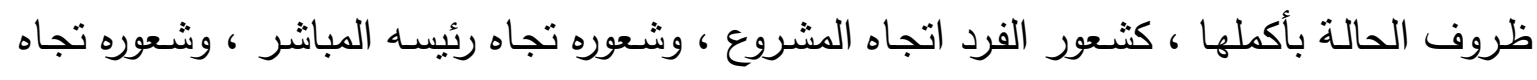

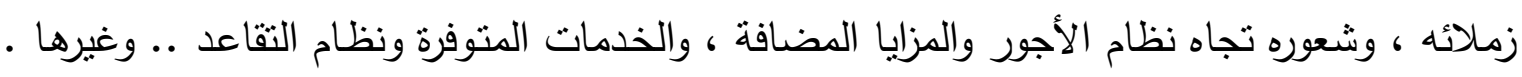

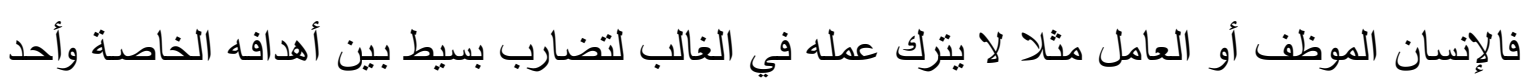

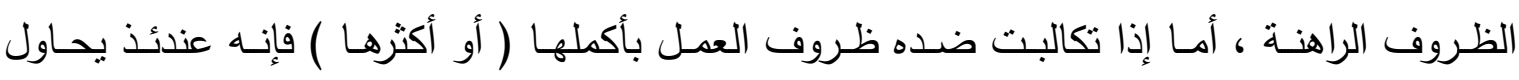

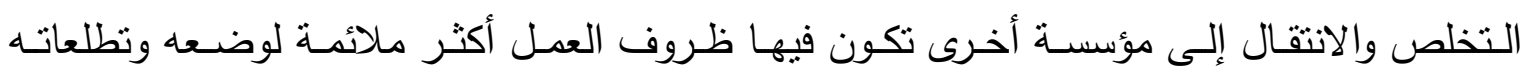

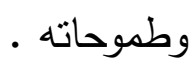
وقد رأى نيومان وسمر أن هناك عددا من الأسباب قد تؤدي إلى نفور الثخص من الوسائل الرقابية

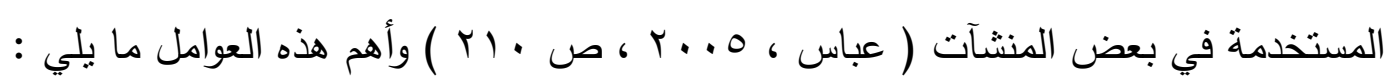

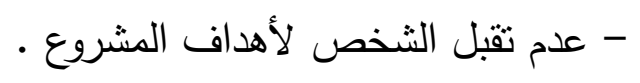
- عدم عقلانية مسنويات الإنجاز المطلوبة . - عدم الثقة بصحة المقاييس المعتمدة . - الضغط من مصادر غير شرعية . - الضغط الاجتماعي الذي ينافي الرقابة الرسمية . 
ولابد من الإثارة إلى هناك أسبابا عديدة قد تدفع الفرد العامل في بعض المنظمات إلى استتكار

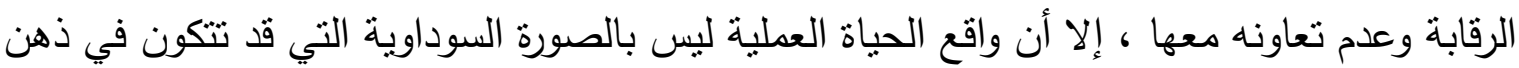
البعض ، فالإدارة الواعية والنشطة والمدبرة يجب أن لا لا تقف مكتوفة الأيدي أمم المناوءات المختلفة

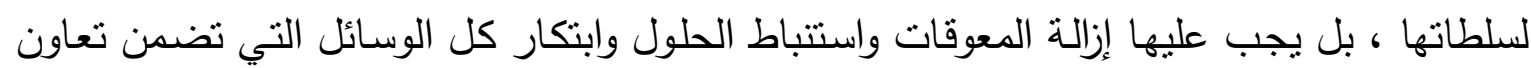

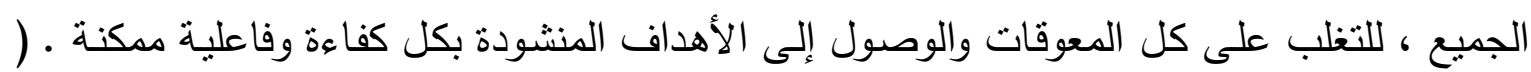

\section{تحليل النتائج واختبار القرضيات :}

فيما يلي عرضا للنتائج التي تم الحصول عليها باستخدام أداة الدراسة ، وبعد إجراء المعالجات الإحصائية

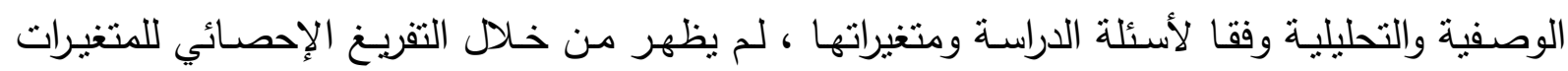

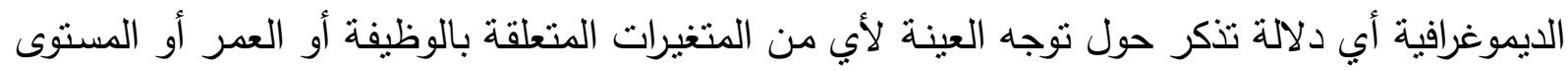

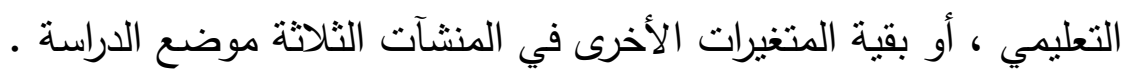

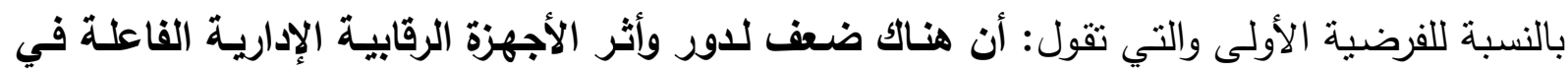

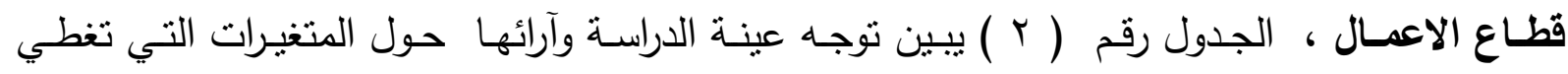
الفرضية الاولى .

جدول رقم (r )

\begin{tabular}{|c|c|c|c|c|c|c|c|c|c|c|c|}
\hline \multirow{2}{*}{ الكسابي } & \multicolumn{2}{|c|}{ لاأتفق نهائيا } & \multicolumn{2}{|c|}{ لا أتفق } & \multicolumn{2}{|c|}{ غير متأكد } & \multicolumn{2}{|c|}{ أثقق } & \multicolumn{2}{|c|}{ أثفق تماما } & \multirow{2}{*}{ المتغير ات } \\
\hline & $\%$ & ت ت تكرار & $\%$ & 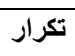 & $\%$ & 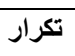 & $\%$ & 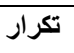 & $\%$ & 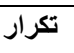 & \\
\hline 3.5 & $1 \leqslant . r$ & ro & 9.7 & iv & 10.9 & $r \wedge$ & Tr.\& & or & TY.A & $\varepsilon 9$ & أنشعر بمتابعة رؤسائي لأعمالي وواجباتي. \\
\hline 3.38 & 17.0 & rq & 10.9 & rی & 15.0 & rr & rT.Y & « & $\mu . \Lambda$ & 07 & هناك متابعات دورية للعمل من قبل الإدارة \\
\hline 3.16 & 1.0 & 10 & rT & $0 \wedge$ & $1 \cdot . r$ & 11 & $r \cdot .1$ & or & $1 A . Y$ & rr & أقوم بمتابعة المرؤوسين وفق جدول منظم مسبقا. \\
\hline 3.88 & $\varepsilon .0$ & $\wedge$ & $V . \varepsilon$ & ir & $1 \cdot . \wedge$ & 19 & rI & $r v$ & $0 . . \mathrm{V}$ & 19 & أعمل على استثارة رؤسائي إذا دعت الحاجة. \\
\hline 3.24 & $19 . r$ & rะ & 17.0 & rq & $Y . \varepsilon$ & ir & r४.1 & $\leq \tau$ & rq & 01 & الأعمال التي أقوم بها مرسومة بدقة وعناية. \\
\hline 4.02 & - & - & $1 \Lambda . Y$ & 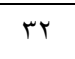 & 1.0 & 10 & Y⿱..Y & $\varepsilon \vee$ & $\sum 7.7$ & Ar & أرى أن أنظمة المتابعة تساعد على سلامة العمل \\
\hline 3.24 & r.^ & 0 & r4.1 & $\varepsilon 4$ & ri.r & 00 & rr.q & $\varepsilon r$ & 17 & ru & المنبعة. \\
\hline 3.8 & \&.Y & ir & 9.7 & iv & 11.2 & $r$. & ra.r & 79 & rT.६ & ov & وأهدافه. بوجود خطط تتسجم مع سير العمل \\
\hline 3.95 & 7.r & 11 & 0.1 & 9 & $1 \Lambda . r$ & rr & $r \cdot . V$ & os & $\varepsilon \cdot, r$ & $\sqrt{1}$ & واجباتي. \\
\hline 3.08 & $0 . Y$ & 1. & rT & $0 \wedge$ & To & $\bar{\varepsilon}$ & $r \cdot .0$ & $r 4$ & 17 & ru & اليومية. \\
\hline 3.78 & «o & $\wedge$ & 9.1 & 17 & $r \leqslant .0$ & $\varepsilon r$ & $r v . r$ & $\varepsilon \wedge$ & $r \varepsilon .$, & 7 & أفضل أن توجيهات الرؤساء تشاعد على إنجاز \\
\hline
\end{tabular}




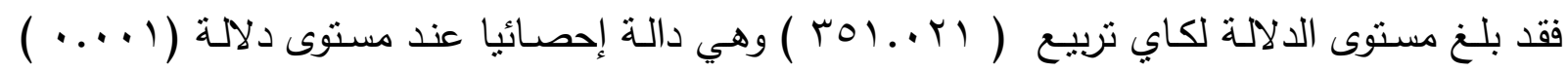

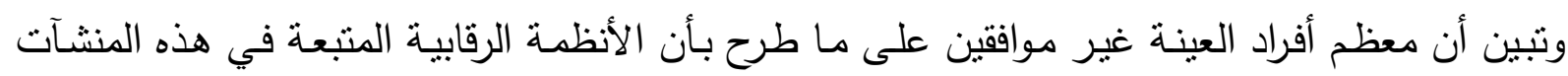

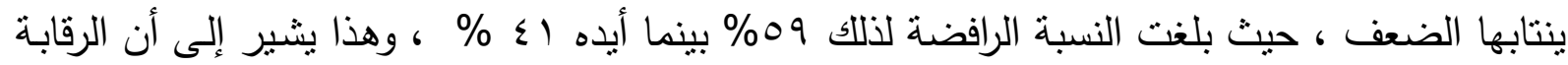

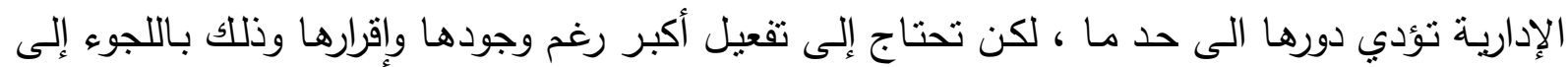

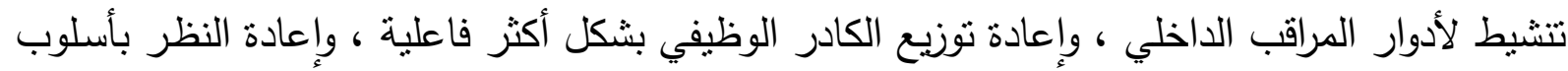

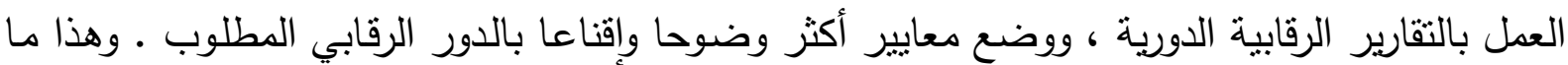

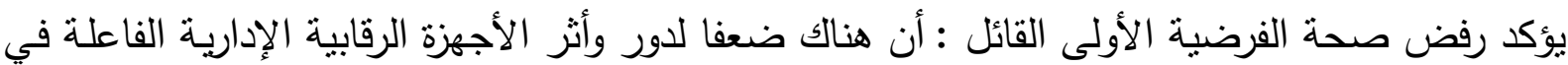

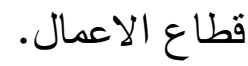
اما الفرضية الثانية والتي تقول :" يلاحظ عدم فاعلية أسـاليب ووسـائل الرقابـة المستخدمة في قطاع

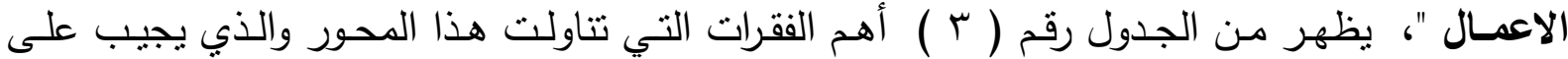

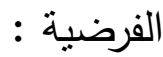

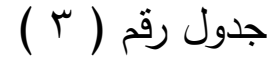

\begin{tabular}{|c|c|c|c|c|c|c|c|c|c|c|c|}
\hline \multirow{2}{*}{ الحسابي } & \multicolumn{2}{|c|}{ لأتفق نهائيا } & \multicolumn{2}{|c|}{ لا أتفق } & \multicolumn{2}{|c|}{ غير متأكد } & \multicolumn{2}{|c|}{ أتفق } & \multicolumn{2}{|c|}{ أتفق تماما } & \multirow{2}{*}{ المتغير ات } \\
\hline & $\%$ & 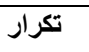 & $\%$ & 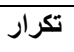 & $\%$ & 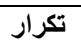 & $\%$ & 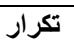 & $\%$ & تكرار & \\
\hline 2.95 & 10.9 & $r \wedge$ & YY.\& & or & $1 \leqslant . Y$ & ro & 10.9 & $r_{\Lambda}$ & $r 1.7$ & $r \Lambda$ & تارس الثهرية الرقابة الإدارية من خلال الثقارير \\
\hline 2.79 & ז૫. & «7 & 11.1 & $r r$ & rT.O & 09 & 0.1 & 9 & 17.0 & rq & تمارس الرقابة الإدارية من خال الزيارات \\
\hline 2.49 & $r \cdot . V$ & $0 \leqslant$ & $\leqslant 0.7$ & $\leq 7$ & $10 . r$ & $r v$ & 19.4 & $r \varepsilon$ & 1.0 & 10 & • تمارس الرقابة الإدارية من خلا الاتصالات \\
\hline 2.68 & YY.Y & $\varepsilon$. & Tr.r & \&1 & $T Y_{.}{ }^{\prime}$ & ¿А & 10.9 & YA & $1 \cdot .1$ & 19 & و ت تمارس الرقابة الإدارية من خال الاجتماعات \\
\hline 3.33 & r9.0 & or & $1 \leqslant . \wedge$ & $r r$ & YY.Y & $\varepsilon$. & IA.Y & rr & $1 \leqslant 0$ & YT & تمارس الرقابة الإدارية من خلال المعايشة \\
\hline 4.47 & - & - & - & - & $v_{\text {. }} \varepsilon$ & $1 \pi$ & rᄉ. ${ }_{1}$ & TV & $0 \leqslant .0$ & 97 & ـ تمارس الرقابة الإدارية من خلال مر اجـــــــة \\
\hline 3.13 & TV.O & $r$. & rY.Y & $\varepsilon$ & $1 \cdot . \wedge$ & 19 & $r 9.0$ & or & 19.9 & ro & 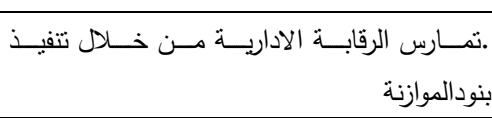 \\
\hline 3.23 & $1 V_{.0}$ & $r$. & 10.9 & $r \wedge$ & 19.5 & $r \varepsilon$ & YY.Y & rq & ro. & «o & ـ تمارس الرقابة الإدارية من خال متابعة تتفيذ \\
\hline 2.39 & $r \varepsilon . Y$ & 71 & ro. 1 & «o & $1 \leqslant . Y$ & ro & 17.0 & $r q$ & 7.1 & 17 & تمارس الرقابة الادارية من خلال الرقابة الذاتية \\
\hline 3.2 & 10.7 & YA & $r \cdot 0$ & ru & $1 \leqslant . Y$ & ro & Y.. & $\leqslant 7$ & rt.r & \&1 & الموظفين و الثنقارير المرفوعة عنهم الإدارية من خلال مر اجعة ملفات \\
\hline 2.58 & YY.Y & rq & $r 1.7$ & $r_{\Lambda}$ & rv & 10 & $1 \leqslant . Y$ & ro & 0.1 & 9 & ـ المعدات وصيانتها الرقابة الإدية من خلال الحفاظ على \\
\hline
\end{tabular}




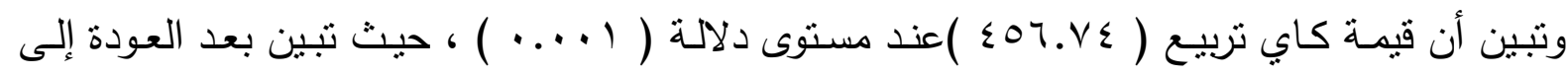

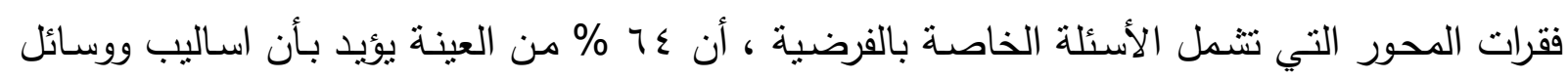

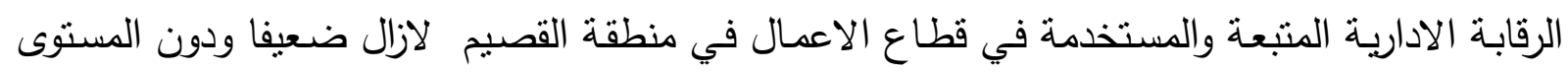

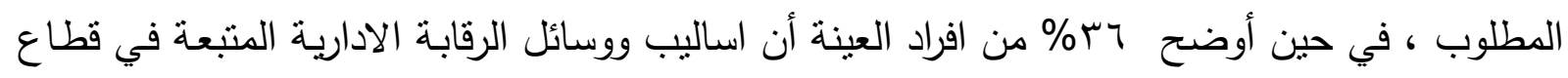

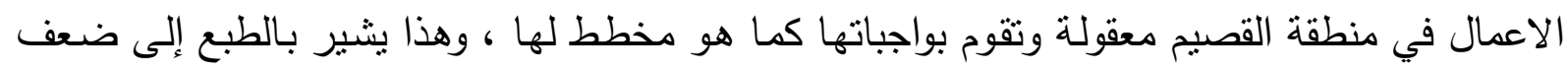

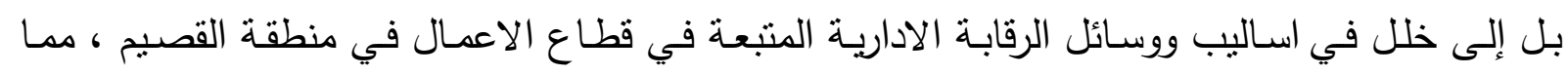

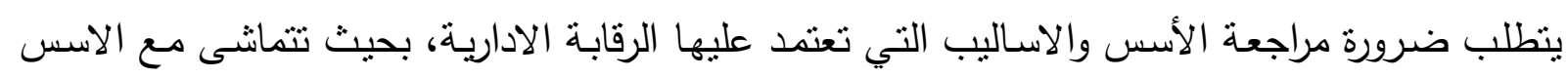

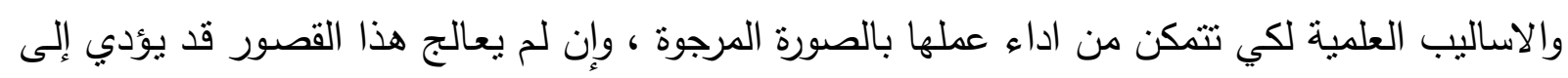

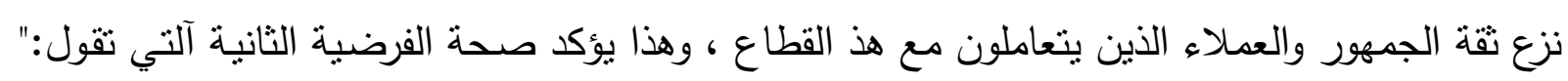

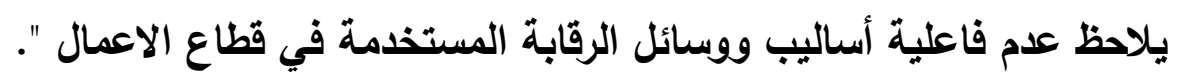

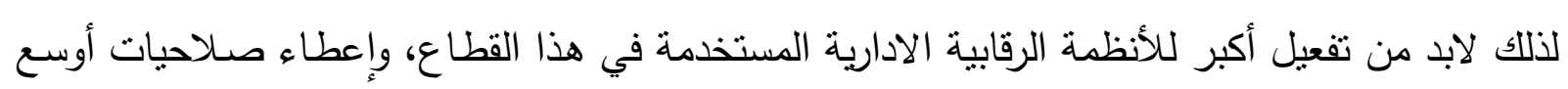

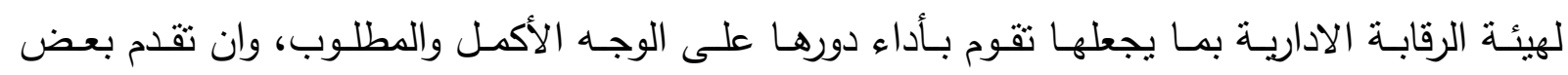

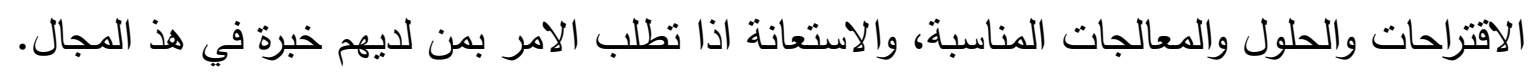

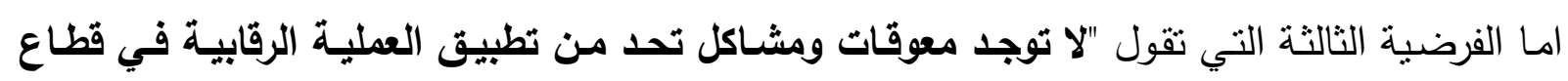

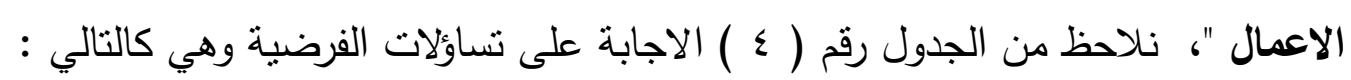

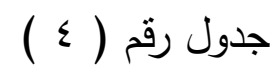

\begin{tabular}{|c|c|c|c|c|c|c|c|c|c|c|c|}
\hline \multirow{2}{*}{ الحسابي } & \multicolumn{2}{|c|}{ لأتفق نهائيا } & \multicolumn{2}{|c|}{ ل أتفق } & \multicolumn{2}{|c|}{ غير متأكد } & \multicolumn{2}{|c|}{ أنفق } & \multicolumn{2}{|c|}{ أتفق تماما } & \multirow{2}{*}{ المتغير ات ـ ـ مقياس الإجابة } \\
\hline & $\%$ & 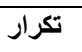 & $\%$ & 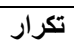 & $\%$ & ت ت تكرار & $\%$ & 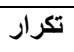 & $\%$ & 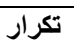 & \\
\hline 2.84 & $r \cdot .1$ & or & YT.T & 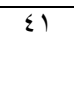 & 10.9 & rA & $1 \% .0$ & rY & $1 \Lambda . Y$ & rY & الرقابة اهتمام من قبل المسؤولين بوظيفة \\
\hline 3.02 & r. 1.7 & rA & $r \cdot r^{r}$ & r & $11 . \varepsilon$ & r. & $r \cdot . \varepsilon$ & $r 4$ & ro. 9 & $\leq 4$ & في الرقابة الادارية فائل الاتصال المستخدمة \\
\hline 2.34 & ए६. $Y$ & 71 & $r \wedge . \varepsilon$ & o. & $1 \% .1$ & $r r$ & 17.0 & rq & $V . \varepsilon$ & ir & 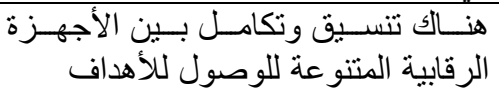 \\
\hline 2.75 & rT.9 & $\varepsilon r$ & ro & $\varepsilon \varepsilon$ & IV.V & r & 11.1 & rr & $1 \leqslant . \varepsilon$ & $r 4$ & تتوفر معايير علمية لقياس الاداء \\
\hline r.97 & זฯ.Y & $\sum v$ & r६. 1 & т. & 17.0 & rq & I६.Y & ro & 1.0 & 10 & يرد فيها اهتمام بالتقارير الرقابية ومتابعة ما \\
\hline r. ro & IV.I & $r$ r. & $1 \leqslant . \varepsilon$ & r & $10 . r$ & rv & $r .7$ & $r_{\Lambda}$ & TI. & 00 & تمارس الرقابة في الوقت المناسب \\
\hline r.o & $\leqslant 1$ & 1) & ro. & «o & 10.9 & rA & 15.7 & $r \varepsilon$ & $1 \cdot r$ & 11 & تلعدد الجهات التي تـارس الرقابة \\
\hline$r . v$ & IV.1 & $r$. & 19.7 & ro & $1 \varepsilon . \varepsilon$ & rT & r.. & $\varepsilon v$ & r’.A & ra & 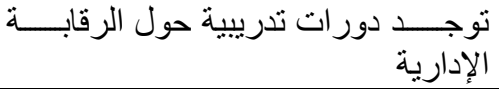 \\
\hline$r . r v$ & 15.1 & rt & 17.0 & rq & $1 \Lambda_{.} \mathrm{r}$ & rt & $\overline{r \varepsilon . Y}$ & $\varepsilon r$ & TV.A & $\leqslant 9$ & ضعف الوعي بالرقابة الذاتية \\
\hline 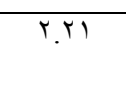 & $r \wedge .7$ & 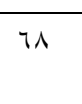 & $r$ r.r & 04 & v. 9 & $1 \varepsilon$ & 15.1 & r & 1.0 & 10 & المساءلة والمحاسبة والعلاقات الثخصية تحول دون \\
\hline T.AV & $r \leqslant .0$ & $\varepsilon$ & 19.9 & ro & IV.Y & $r$ & $r \cdot . \xi$ & $r 4$ & IV.Y & r & الضغوط الاجتماعية تؤثر على الرقابة \\
\hline
\end{tabular}




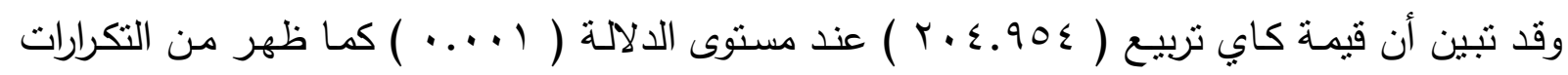

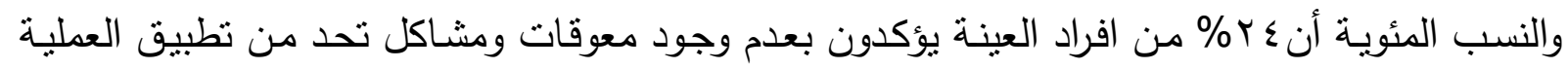

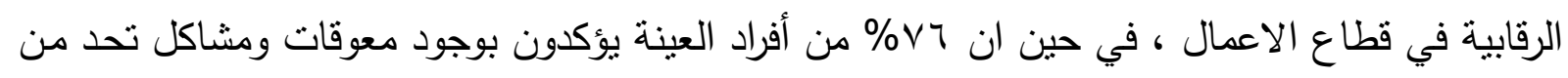

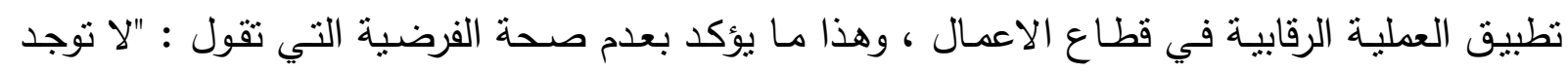

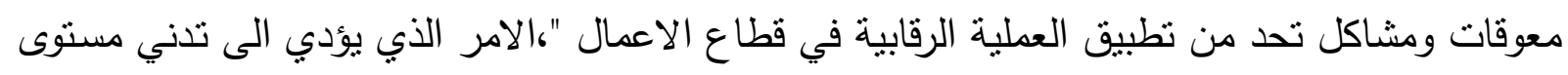

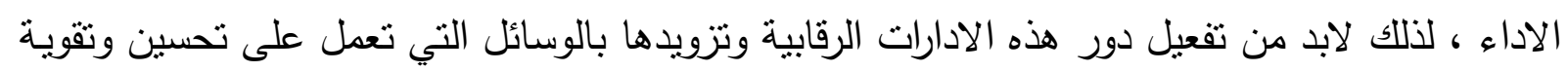

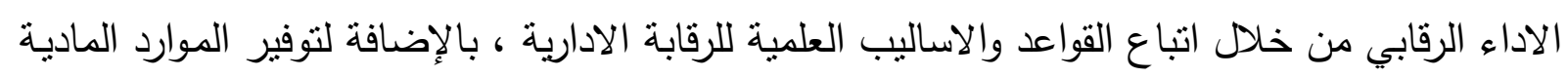

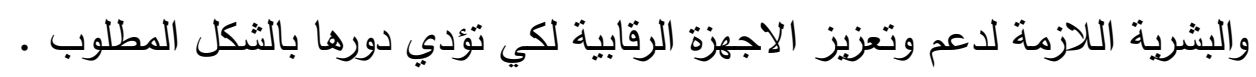

\section{وقد توصلت الدراسة إلى النتائج التالية :

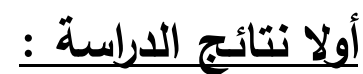

تتلخص أهم الاستتتاجات التي توصلت إليها الدراسة في الآتي :

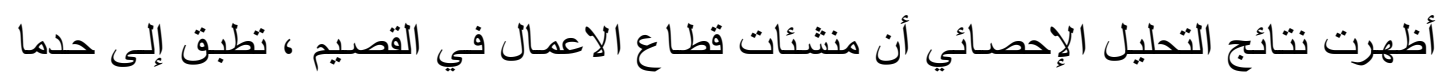

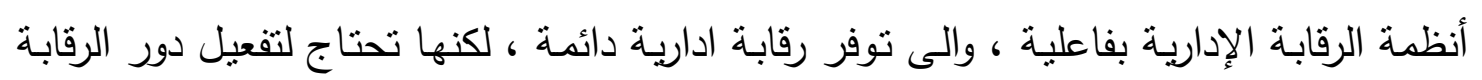

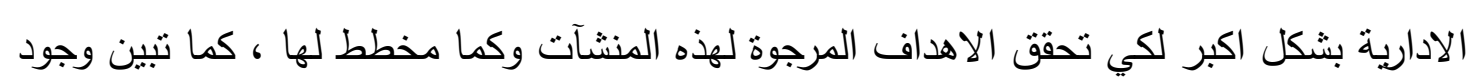

$$
\text { ضعف والى حد ما }
$$

في اداء وظيفة الرقابة الادارية في قطاع الاعمال .

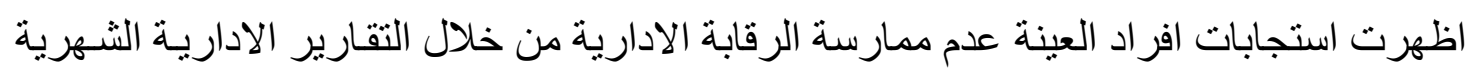

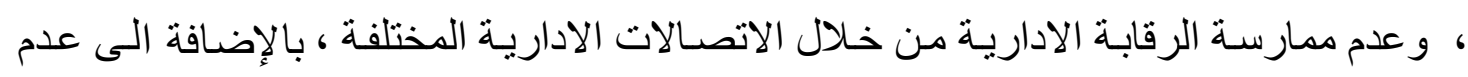

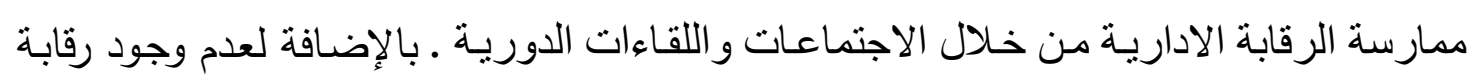

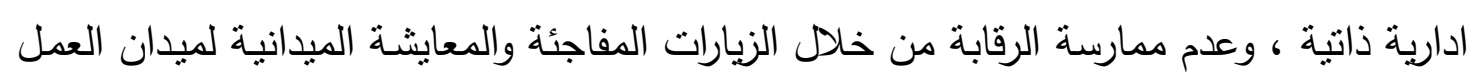

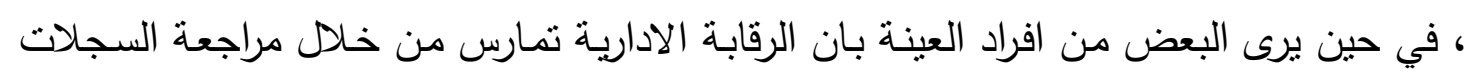

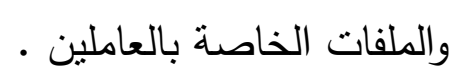

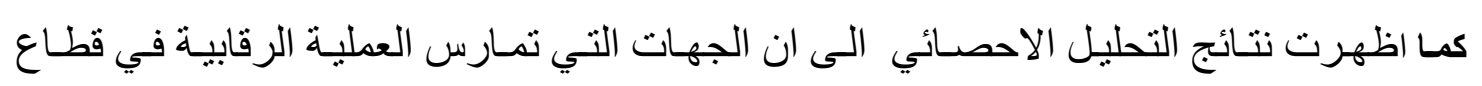

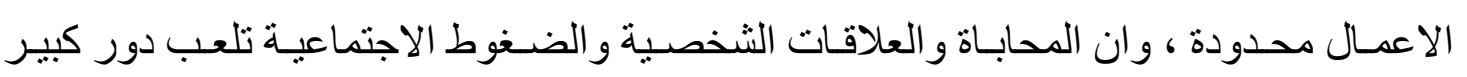

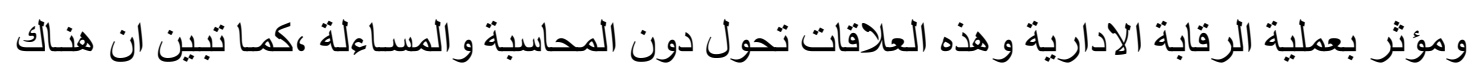

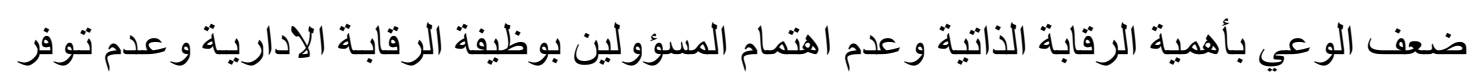

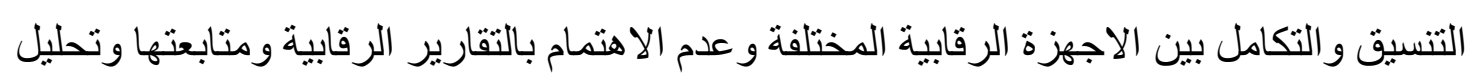

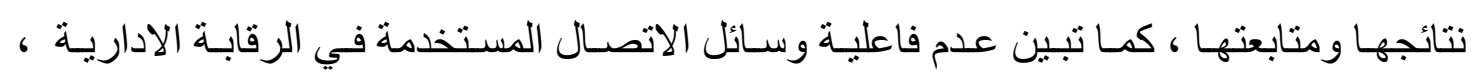


بالإضافة الى عدم توفر المعايير العلمية المناسبة لقياس كفاءة الاداء للعاملين و التي بدورها تؤثر

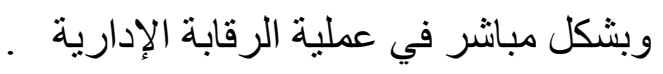

\section{ثُانيا التوصيات :}

لعل من أبرز التوصيات التي تم التوصل اليها تتلخص فيما يلي:

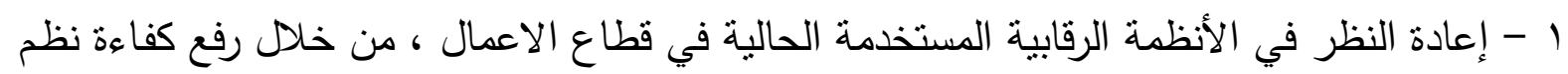

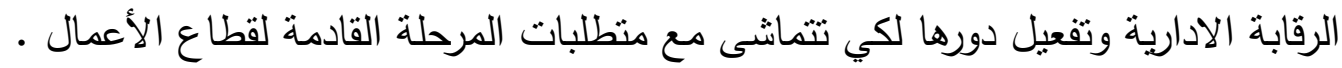

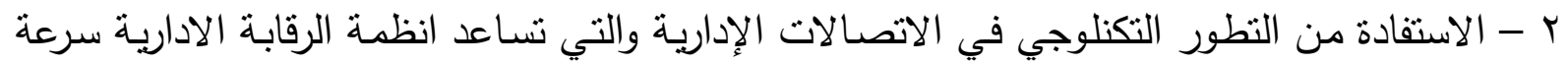

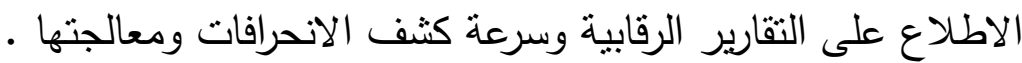
r- العمل على بناء ثقافة تنظيمية تثجع وتكسب العاملين القيم والسلوكيات الحميدة والتي تعمل كأدوات

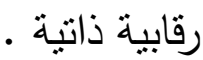
ع - تفعيل وتطوير الاساليب الرقابية المستخدمة ، واستحداث انظمة رقابية فاعلة تواكب التطور والنقدم

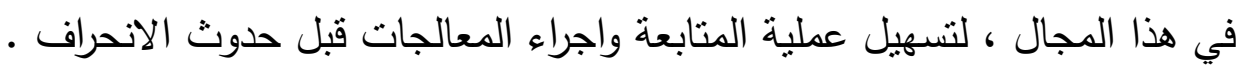
0- تطوير وزيادة البرامج التنريبية حول الرقابة الادارية . 7- رفع مستوى الوعي لاى العاملين والدسؤولين في قطاع الاعمال ، بأهمية ممارسة الرقابة الادارية لرفع الارية

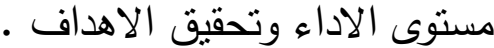




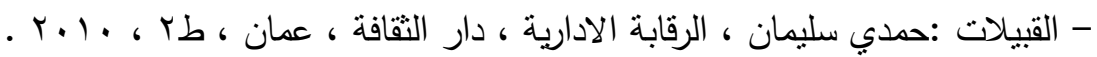

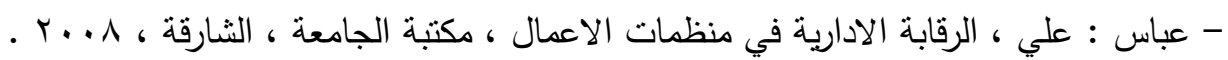

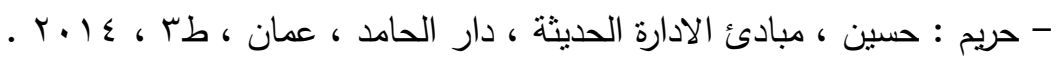

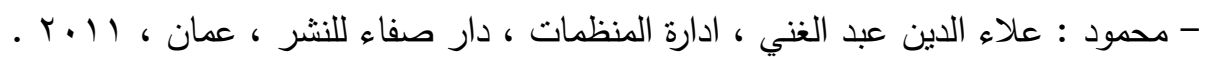

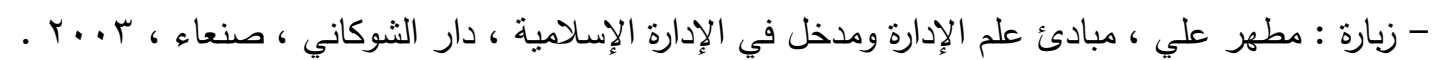

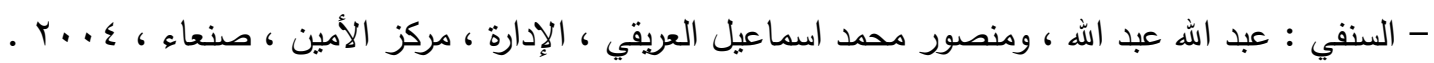

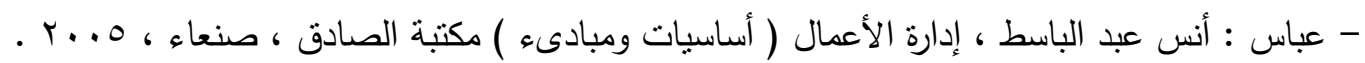

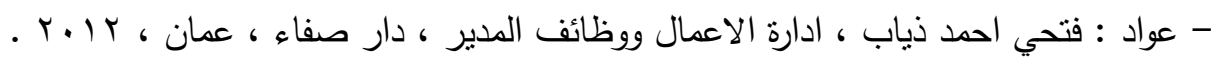

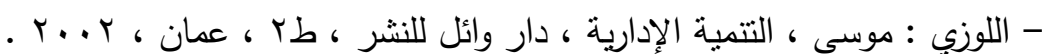

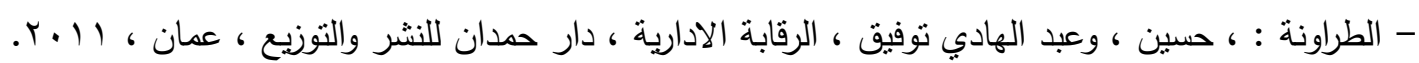

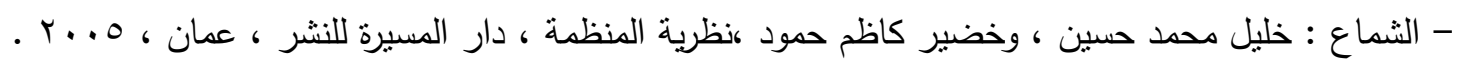

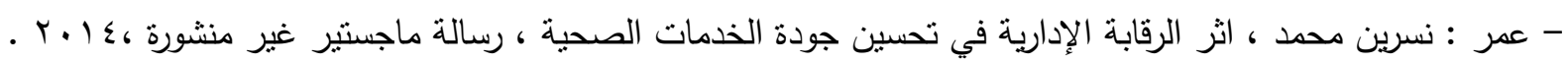

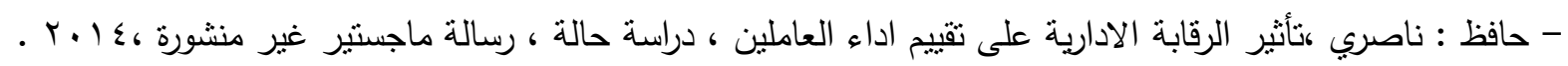

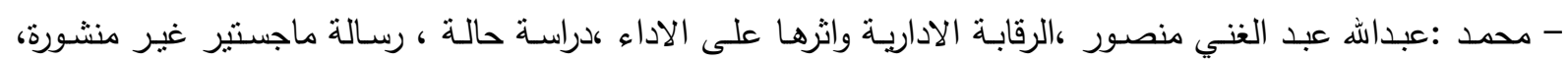

- العرموطي: عامر صـالح ، مدى فاعلية الرقابـة الداخليـة في المنشـآت الصغيرة ومتوسطة الحجم في الاردن، رسـالة

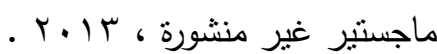

- Chih,(2007), Internal control enterprise risk management and firm performance. University Of Mary Land. United State.

- Ivancevich, John Lorenzi, Peter, Skinner, Steven and Crosby Philip (1999), Management; Quality and Competitiveness, $2^{\text {nd }}$ ed., Boston, Mcraw-Hill.

- Norio and Shuichi,(2013), The role of middle management and management control in health care. Koyto University. Japan.

- Robbins, Stephen and Coulter, Mary (1999), Management, $6^{\text {th }}$ ed., Upper Saddle River, N. J. : Prentice-Hall.

- Shujun,(2007), Effect of mood and management control system on performance evaluation. University Of Calgry. United State.

- Stephen p and Mary, (2009), Management, United State. 